\title{
Liquid-state NMR analysis of nanocelluloses
}

\section{King, Alistair William Thomas}

2018-07

King , A W T , Mäkelä , A V , Kedzior , S , Laaksonen , T M , Partl , G J , Heikkinen , S M , Koskela , H T , Heikkinen , H A , Holding , A , Cranston , E \& Kilpeläinen , I A 2018 , ' Liquid-state NMR analysis of nanocelluloses ', Biomacromolecules, vol. 19 , no. 7 , pp. pÿ2708 2720 . https://doi.org/10.1021/acs.biomac.8b00295

http://hdl.handle.net/10138/301168

https://doi.org/10.1021/acs.biomac.8b00295

other

publishedVersion

Downloaded from Helda, University of Helsinki institutional repository.

This is an electronic reprint of the original article.

This reprint may differ from the original in pagination and typographic detail.

Please cite the original version. 


\title{
Liquid-State NMR Analysis of Nanocelluloses
}

Alistair W. T. King, ${ }^{* \dagger \oplus}$ Valtteri Mäkelä, ${ }^{\dagger}$ Stephanie A. Kedzior, ${ }^{\ddagger}, \# \oplus$ Tiina Laaksonen, ${ }^{\dagger}$ Gabriel J. Partl, ${ }^{\dagger}$ Sami Heikkinen, ${ }^{\dagger}$ Harri Koskela, ${ }^{\S}$ Harri A. Heikkinen, $\|$ Ashley J. Holding, ${ }^{\dagger, \perp}$ Emily D. Cranston, ${ }^{\ddagger}$ and Ilkka Kilpeläinen* ${ }^{\dagger}$

\author{
${ }^{\dagger}$ Materials Chemistry Division, Chemistry Department, University of Helsinki, AI Virtasen Aukio 1, Helsinki, Finland \\ ${ }^{\ddagger}$ Department of Chemical Engineering, McMaster University, Hamilton, Ontario, Canada \\ ${ }^{\S}$ The Finnish Institute for Verification of the Chemical Weapons Convention (VERIFIN), University of Helsinki, AI Virtasen Aukio 1, \\ Helsinki, Finland \\ "The Finnish Biological NMR Center, Biocenter 3, University of Helsinki, Viikinkaari 1, Helsinki, Finland \\ ${ }^{\perp}$ Worn Again Technologies Ltd, Biocity, Pennyfoot Street, Nottingham, United Kingdom
}

Supporting Information

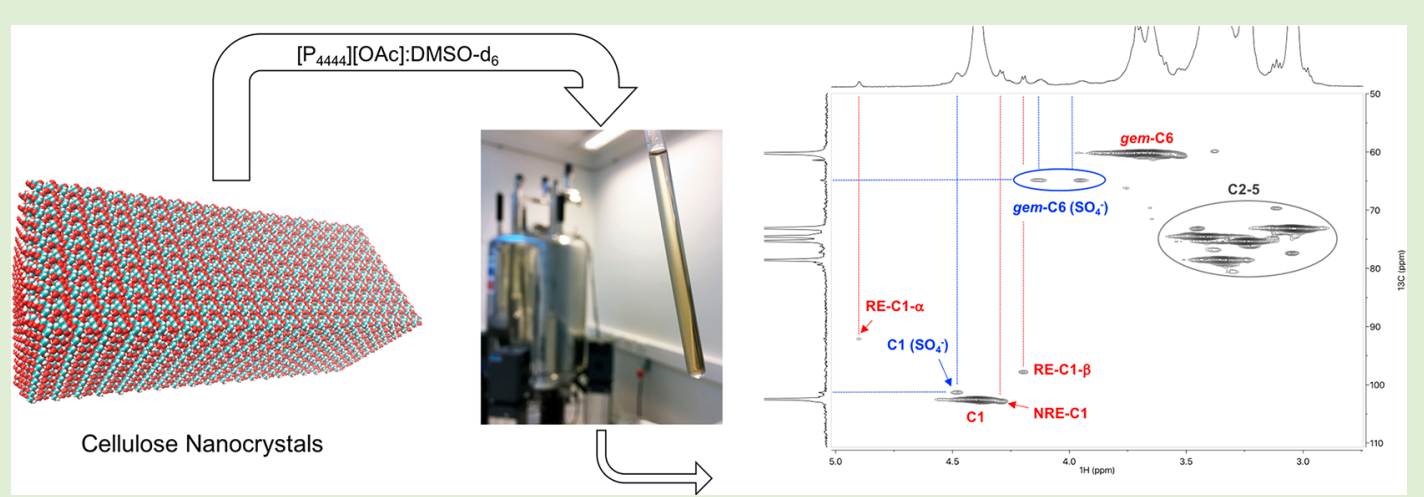

ABSTRACT: Recent developments in ionic liquid electrolytes for cellulose or biomass dissolution has also allowed for highresolution ${ }^{1} \mathrm{H}$ and ${ }^{13} \mathrm{C}$ NMR on very high molecular weight cellulose. This permits the development of advanced liquid-state quantitative NMR methods for characterization of unsubstituted and low degree of substitution celluloses, for example, surfacemodified nanocelluloses, which are insoluble in all molecular solvents. As such, we present the use of the tetrabutylphosphonium acetate $\left(\left[\mathrm{P}_{4444}\right][\mathrm{OAc}]\right): \mathrm{DMSO}-d_{6}$ electrolyte in the $1 \mathrm{D}$ and $2 \mathrm{D}$ NMR characterization of poly(methyl methacrylate) (PMMA)grafted cellulose nanocrystals (CNCs). PMMA- $g$-CNCs was chosen as a difficult model to study, to illustrate the potential of the technique. The chemical shift range of $\left[\mathrm{P}_{4444}\right][\mathrm{OAc}]$ is completely upfield of the cellulose backbone signals, avoiding signal overlap. In addition, application of diffusion-editing for ${ }^{1} \mathrm{H}$ and HSQC was shown to be effective in the discrimination between PMMA polymer graft resonances and those from low molecular weight components arising from the solvent system. The bulk ratio of methyl methacrylate monomer to anhydroglucose unit was determined using a combination of HSQC and quantitative ${ }^{13} \mathrm{C}$ NMR. After detachment and recovery of the PMMA grafts, through methanolysis, DOSY NMR was used to determine the average self-diffusion coefficient and, hence, molecular weight of the grafts compared to self-diffusion coefficients for PMMA GPC standards. This finally led to a calculation of both graft length and graft density using liquid-state NMR techniques. In addition, it was possible to discriminate between triads and tetrads, associated with PMMA tacticity, of the PMMA still attached to the CNCs (before methanolysis). CNC reducing end and sulfate half ester resonances, from sulfuric acid hydrolysis, were also assignable. Furthermore, other biopolymers, such as hemicelluloses and proteins (silk and wool), were found to be soluble in the electrolyte media, allowing for wider application of this method beyond just cellulose analytics.

\section{INTRODUCTION}

Nanocellulose, that is, cellulose nanocrystals (CNCs), cellulose nanofibrils (CNFs), and bacterial nanocellulose (BNC), is currently being intensively researched for its applications, mainly in life science and materials engineering. ${ }^{1-3}$ Many niche applications are under development, but for high volume applications, the areas of interest are primarily in the spinning or casting of nanocelluloses and their composites (e.g., as films $s^{4,5}$ and fibers for textile applications ${ }^{6-9}$ ), as emulsion/foam stabilizers, $^{10-14}$ or as rheological modifiers ${ }^{15-17}$ and in packaging. ${ }^{18-20}$ Many of these applications require topochemical modification, that is, at the nanocellulose surface,

Received: February 21, 2018

Revised: April 3, 2018

Published: April 3, 2018 
to tune dispersion and interactions with components in particular media. ${ }^{21}$ Typical examples of chemical modifications that help to enhance the dispersion of nanocelluloses are (2,2,6,6-tetramethylpiperidin-1-yl)oxyl (TEMPO) oxidation, ${ }^{22-26}$ sulfate half ester formation during hydrolysis, ${ }^{27}$ and carboxymethylation. ${ }^{28}$ These methods introduce electrostatic charge on the surface of the nanocellulose, which aids in initial dispersion and redispersion in polar media. Many of these methods are expediently applied during the initial preparation and isolation stages using water as the reaction media. Further chemical modifications can then be applied, commonly to residual hydroxyl or carboxylate functionalities, to further tune dispersibility, phase-behavior or to introduce additional functionality. Specific modifications of interest for bulk application include grafting polymers to, or from, the surface of nanocelluloses. These are often through etherification or esterification, as typical reaction pathways. ${ }^{29}$ The degree of polymerization (DP, i.e., chain length) and graft density can be tuned, as is in the case of atom transfer radical polymerization (ATRP), ${ }^{30-34}$ although this method is typically reserved for model studies due to the high cost associated with the number of required steps and isolation procedures. Alternatively, a potentially cheaper industrial method is through radicalinitiated grafting, minimizing the number of steps required. ${ }^{35-37}$ However, with this technique, the introduction of radicals and grafting of monomers does not have very specific chemoselectivity and regioselectivity. As such, mechanistic understanding and selectivity of the chemistry is difficult to come by in such heterogeneous systems.

Direct methods (not involving derivatization) to characterize celluloses, which are modified to very low degrees of substitution (DS), are severely limited. Klemm et al., ${ }^{38}$ have identified this as a future challenge in cellulose analytics. This is due to the insolubility of very low DS, heterogeneously modified and surface-modified technical celluloses, in all common molecular solvents. As such, current direct methods are all based on solid-state analyses. These are at best semiquantitative and include X-ray photoelectron spectroscopy (XPS), ${ }^{13} \mathrm{C}$ cross-polarization magic angle spinning (CP-MAS) nuclear magnetic resonance (NMR), ${ }^{1} \mathrm{H}$ high resolution magic angle spinning (HR-MAS) NMR, attenuated total reflection (ATR)-FTIR spectroscopy, and elemental analysis. Solutionphase analyses, after hydrolysis, are even more problematic as, for example, CNCs are both insoluble in common molecular solvents and are even unreactive in $<65 \%$ sulfuric acid due to their highly crystalline state. Avoiding degradation of key functionalities under such acidic conditions is very difficult. However, there is demonstrated potential for liquid-state quantitative analyses after dissolution into direct-dissolution solvents, such as ionic liquids. These problems are not restricted to nanocellulose alone but apply to all celluloses which retain crystalline regions. For example, topochemically modified celluloses or celluloses reacted to very low DS, under homogeneous or heterogeneous conditions. Thus, a general method for liquid-state analysis, preferably NMR-based, is needed.

Recently we demonstrated the dissolution and NMR analysis of different technical cellulosic pulps in the ionic liquid electrolyte methyltrioctylphosphonium acetate $\left(\left[\mathrm{P}_{8881}\right]\right.$ $[\mathrm{OAc}]): \mathrm{DMSO}-d_{6 \cdot}{ }^{39}$ Using this system, it was possible to even acquire ${ }^{1} \mathrm{H}-{ }^{13} \mathrm{C}$ heteronuclear single quantum correlation (HSQC) NMR spectra from high molecular weight samples, such as bacterial cellulose, due to the excellent solvating power of the electrolyte, at the concentrations prepared. However, the high concentrations of the $\left[\mathrm{P}_{8881}\right][\mathrm{OAc}]$ salt and the fact that most of the alkyl positions on the octyl chains all occur at $\sim 1.5$ ppm means that the relative $\mathrm{S} / \mathrm{N}$ of cellulose is still quite low, potentially limiting dynamic range and resolution.

Therefore, we present our results detailing the use of an improved phosphonium-based ionic liquid electrolyte and the most suitable methods for analysis of low-DS celluloses. As such, a difficult-to-analyze model, of modified nanocellulose, was chosen to illustrate this method. This was poly(methylmethyl acrylate)-grafted cellulose nanocrystals (PMMA-g-CNCs), prepared previously by Kedzior et al. ${ }^{37}$ through ceric ammonium nitrate (CAN, free radical) initiated grafting of methyl methacrylate (MMA). ${ }^{37}$ The PMMA-gCNCs were determined to have similar dimensions and crystallinity (Cellulose I) to the starting "pristine" CNCs. Grafting was confirmed using ${ }^{13} \mathrm{C}$ CP-MAS NMR, contact angle (increased hydrophobicity), thermogravimetric analysis (TGA), and XPS. However, the degree of incorporation of MMA monomer versus cellulose anhydroglucose unit (AGU), the graft density and, hence, also the graft length, could not be accurately determined.

In the present publication, we succeeded in determining the PMMA graft length and the graft density of the PMMA- $g$-CNC samples using a combination of quantitative ${ }^{1} \mathrm{H}$ and ${ }^{13} \mathrm{C} \mathrm{NMR}$, diffusion-ordered spectroscopy (DOSY), and HSQC variants, to investigate the possibility of identifying polymeric signals or editing out our ionic liquid signals, increasing resolution. The elusive low-abundance sulfate half ester resonances were also identified, in ${ }^{1} \mathrm{H}$ and ${ }^{13} \mathrm{C}$ detected experiments, due to the high resolution offered by the liquid-state analysis. This also allowed for the study of the tacticity of the PMMA grafts, while still attached to the cellulose backbone.

In addition, we also tested the solubility of different biopolymers, such as hemicelluloses and proteins (silk and wool), to demonstrate the potential wider applicability of the method.

\section{EXPERIMENTAL SECTION}

Preparation of the PMMA-g-CNCs (Model Nanocellulose). PMMA-g-CNCs were prepared using the procedure by Kedzior et al. ${ }^{37}$ following the scheme in Figure 1. In short, methyl methacrylate

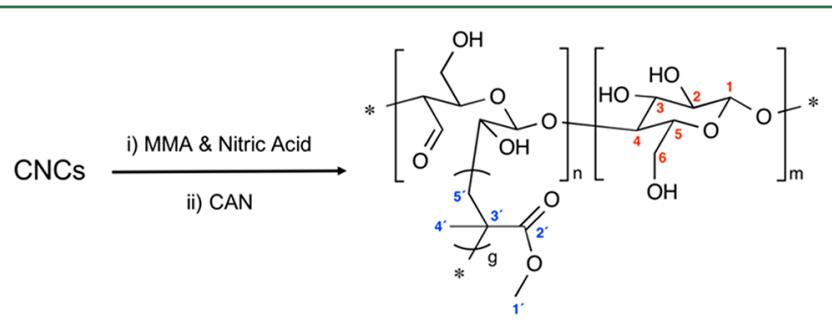

Figure 1. Preparation of PMMA- $g-\mathrm{CNC}$ and carbon numbering scheme used throughout the manuscript. ${ }^{37}$

(MMA) and nitric acid were added to sulfuric acid hydrolyzed pristine CNCs dispersed in water. Under constant probe sonication, the reaction was initiated by addition of ceric ammonium nitrate (CAN) in an ice bath. The PMMA- $g$-CNCs were then purified by centrifugation and stirred cell ultrafiltration in acetone. They were then solvent exchanged back to water, dialyzed against pure water and finally freezedried for further analysis.

Additional Cellulose Samples for NMR Analysis. In addition to the PMMA-g-CNCs, a starting cotton filter paper (FP) was used to prepare the pristine CNCs, through sulfuric acid hydrolysis. Both were 
analyzed for comparison against the PMMA- $g$-CNCs. The filter paper was also grafted with PMMA through an ATRP approach to give PMMA- $g$-FP, for graft methanolysis studies. A sacrificial initiator was used to allow for recovery of homopolymer (SI-PMMA), for graftlength determination. Microcrystalline cellulose (MCC) was used in initial solubilization trials. A sodium cellulose sulfate $(\mathrm{NaCS})$ standard sample was also prepared from MCC, for sulfate resonance identification. Finally, hemicelluloses, silk, wood, chitosan and chitin were also used for additional biopolymer solubility studies. Full information for the source or preparation of all materials is given in the Supporting Information.

Preparation of [ $\left.\mathrm{P}_{4444}\right][\mathrm{OAc}]: \mathrm{DMSO}-d_{6}$ (NMR Solvent). Tetrabutylphosphonium acetate $\left(\left[\mathrm{P}_{4444}\right][\mathrm{OAc}]\right)$ was prepared according to an improved method, based on a previous publication (Figure 2$).{ }^{40}$

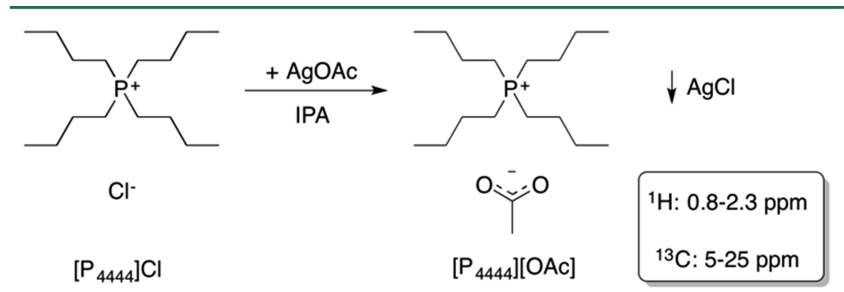

Figure 2. Preparation of $\left[\mathrm{P}_{4444}\right][\mathrm{OAc}]$ and the spectral regions which the alkyl signals occupy.

Initially, tetrabutylphosphonium chloride $\left(\left[\mathrm{P}_{4444}\right] \mathrm{Cl}\right)$ was prepared fresh from the reaction of tri- $n$-butylphosphine with $n$-butyl chloride in a pressurized reactor. This offered slightly better purity than the commercial $\left[\mathrm{P}_{4444}\right] \mathrm{Cl}$ as they typically contain isomers derived from use of technical grades of tri- $n$-butylphosphine. $\left[\mathrm{P}_{4444}\right] \mathrm{Cl}$ was then converted to $\left[\mathrm{P}_{4444}\right][\mathrm{OAc}]$, by metathesis reaction with silver acetate in isopropyl alcohol (IPA), followed by filtration to remove excess salts and silver metal. However, potassium acetate in IPA was also found to be effective, allowing for almost complete exchange of acetate for chloride and reduction in the residual inorganic salt concentration, by precipitation with chloroform. The full procedures are given in the Supporting Information.

To prepare the stock NMR electrolyte solution, $\left[\mathrm{P}_{4444}\right][\mathrm{OAc}]$ was added to DMSO- $d_{6}$ in the $\mathrm{w} / \mathrm{w}$ ratio of $1: 4$. This was found to be sufficient for dissolution of MCC (standard sample for preliminary experiments) up to about $8 \mathrm{wt} \%$ before increasing viscosity made rapid dissolution and transfer of the solution to the $5 \mathrm{~mm}$ NMR tube difficult, without more intense heating. Thus, in most cases, $5 \mathrm{wt} \%$ cellulose in the electrolyte is optimal for sample preparation and spectral resolution.

To dissolve the samples, $\left[\mathrm{P}_{4444}\right][\mathrm{OAc}]: \mathrm{DMSO}-d_{6}(1: 4 \mathrm{w} / \mathrm{w}, 950$ $\mathrm{mg}$ ) was added to the modified or unmodified cellulose samples (50 $\mathrm{mg}$ ) in a $4 \mathrm{~mL}$ sealable sample vial and heated at $65^{\circ} \mathrm{C}$, under argon, for $1 \mathrm{~h}$. The samples were initially dispersed with a fine needle to avoid formation of gelled cellulose, which would dissolve over a longer period. Some samples, for example, filter paper, required longer time to dissolve due to higher molecular weight. For the CNC samples, it was also possible to stir the samples at room temperature to dissolve them over a slightly longer period. This was aided by their low molecular weight, compared to unhydrolyzed celluloses but also their low density after freeze-drying. Once the solutions were clear, the samples were then transferred into a $5 \mathrm{~mm}$ NMR tube for analysis.

Graft Cleavage Procedure. PMMA-g-CNCs were treated with a mixture of $1.27 \mathrm{M}$ acetyl chloride in methanol (to generate $1.27 \mathrm{M}$ hydrochloric acid in methanol) at $80{ }^{\circ} \mathrm{C}$ for $18 \mathrm{~h}$. After the treatment, the system was rotary evaporated to dryness and extracted into $\mathrm{CDCl}_{3}$. DOSY NMR, utilizing the convection-compensated bipolar pulse pair stimulated echo (CC-BPPSTE), ${ }^{41,42}$ pulse sequence was performed directly on this sample to determine the PMMA graft number-average degree of polymerization $\left(\mathrm{DP}_{n}\right)$ against DOSY-analyzed PMMA gelpermeation chromatography (GPC) standards.

NMR Experiments. Standard ${ }^{1} \mathrm{H}$ and ${ }^{13} \mathrm{C}$ NMR experiments were recorded for all samples. Quantitative ${ }^{13} \mathrm{C}$ (inverse gated decoupling), gradient-selected $\mathrm{HSQC}{ }^{43}$ multiplicity-edited ${ }^{44-47} \mathrm{HSQC}$, CarrPurcell-Meiboom-Gill (CPMG $\left.{ }^{48,49}\right)$-filtered HSQC, ${ }^{50}$ diffusionedited HSQC and 1D diffusion-edited HSQC experiments were collected for the PMMA-g-CNC sample. The diffusion-edited HSQC sequence is further described in the Results and Discussion section titled "Diffusion-Editing for Additional Spectral Quality" and full parameters are given in the Supporting Information. DOSY (CCBPPSTE) experiments were set up for analysis of the cleaved PMMA grafts, PMMA GPC standards $\left(5 \mathrm{mg}\right.$ in $1 \mathrm{~mL}$ of $\left.\mathrm{CDCl}_{3}\right)$ and for the diffusion-edited ${ }^{1} \mathrm{H}$ experiments (further details in the Results and Discussion section and the Supporting Information). All spectra were processed using MestReNova 10.0, ${ }^{51}$ except the DOSY spectra, which were processed using "DOSY Toolbox" by Nilsson et al. ${ }^{52,53}$ Selfdiffusion coefficients $\left(D_{i}, \mathrm{~m}^{2} / \mathrm{s}\right)$ for the PMMA methyl ester $\left(D_{\text {Polm }}\right)$ and residual $\mathrm{CHCl}_{3}\left(D_{\text {Solv }}\right)$ were determined using the DOSY module in "DOSY Toolbox" as follows: A $20 \mathrm{~Hz}$ Gaussian line broadening was applied and each increment was phased individually. Only the methyl ester and residual $\mathrm{CHCl}_{3}$ regions were selected. A threshold was also applied to limit additional peaks on the baseline. Monoexponential fitting was then performed that yielded the self-diffusion coefficients for the two resonances.

All of the experiments for cellulose were recorded using a Varian UNITY INOVA $600 \mathrm{MHz}$ spectrometer. All experiments, except the 1D ${ }^{13} \mathrm{C}$ experiments, were recorded using a $5 \mathrm{~mm}$ triple resonance gradient probe. The $1 \mathrm{D}{ }^{13} \mathrm{C}$ experiments were recorded using a $5 \mathrm{~mm}$ broadband probe, designed to maximize ${ }^{13} \mathrm{C}$ signal-to-noise $(\mathrm{S} / \mathrm{N})$.

The Bruker and Varian (Agilent)-format pulse sequences for the diffusion-edited HSQC sequences are given in the Supporting Information and are also available from the authors.

Calculation of Graft Ratio, Length, and Density. The relative self-diffusion coefficients $\left(D_{\text {REL }}\right)$ were obtained using eq 1 , where $D_{\text {Polym }}$ and $D_{\text {Solv }}$ are the self-diffusion coefficients for polymer and $\mathrm{CHCl}_{3}$, respectively. $D_{\text {REL }}$ for PMMA GPC standards were plotted against their $\mathrm{DP}_{n}$ values. This yielded a master curve, which could be fitted with a power law relationship $\left(x=1.085, y=0.61, R^{2}=0.99\right)$, yielding eq 2 , to calculate $\mathrm{DP}_{n}$ directly from $D_{\mathrm{REL}}$ for cleaved grafts. This method of determination of polymer molecular mass is based on work by Crutchfield et al. ${ }^{54}$

$$
\begin{aligned}
& D_{\text {REL }}=\frac{D_{\text {Polym }}}{D_{\text {Solv }}} \\
& \mathrm{DP}_{n}=\frac{x}{D_{\text {REL }}^{y}}
\end{aligned}
$$

The PMMA graft to cellulose AGU ratio $\left(R_{\mathrm{G} / \mathrm{AGU}}\right)$ was determined from quantitative ${ }^{13} \mathrm{C}$ NMR by integrating the cellulose resonances against the PMMA resonances that were not overlapping with $\left[\mathrm{P}_{4444}\right][\mathrm{OAc}]$ or each other. The simplest way to obtain the $R_{\mathrm{G} / \mathrm{AGU}}$ ratio is to calculate the integral value corresponding to a single carbon $\left(I_{1 \mathrm{C}}\right)$ for each compound by summing all included integral regions $\left(I_{x}\right)$ and dividing the sum by the corresponding number of carbons $\left(N_{\mathrm{C}}\right)$, thereby minimizing errors arising from single integral region (eq 3 ). The value obtained for the graft (PMMA) can then be divided by the value for cellulose (AGU), according to eq 4 . The integral regions utilized for cellulose were the $\mathrm{C} 1$ region, $\mathrm{C} 2-5$ regions, and $\mathrm{C} 6$ region $\left(N_{\mathrm{C}}=6\right)$. For PMMA, the integral regions were $\mathrm{C}^{\prime}, \mathrm{C1}^{\prime}$, and $\mathrm{C5}^{\prime}$ regions and $\mathrm{C}^{\prime}\left(N_{\mathrm{C}}=4\right)$. The two equations can also be combined to yield a more concise form (eq 5). The possible errors and abnormal deviations in the integrals can be seen more clearly by looking at normalized integral values: by dividing the raw integral value of each region with the average value determined for a single carbon for the compound $\left(I_{1 \mathrm{C}}\right)$ and further dividing by the number of carbons corresponding to the integral region $\left(N_{\mathrm{C}(\mathrm{X})}\right)$, a normalized integral value $\left(I_{\text {norm }(x)}\right)$ is obtained. These values should be close to 1 . It is then easy to see if some of the integrals are abnormally large or small and to also calculate the relative standard deviation for all of the integrals, obtained from a single compound. The graft density $\left(\sigma_{\mathrm{G}}\right)$ was finally determined according to eq 7 . 

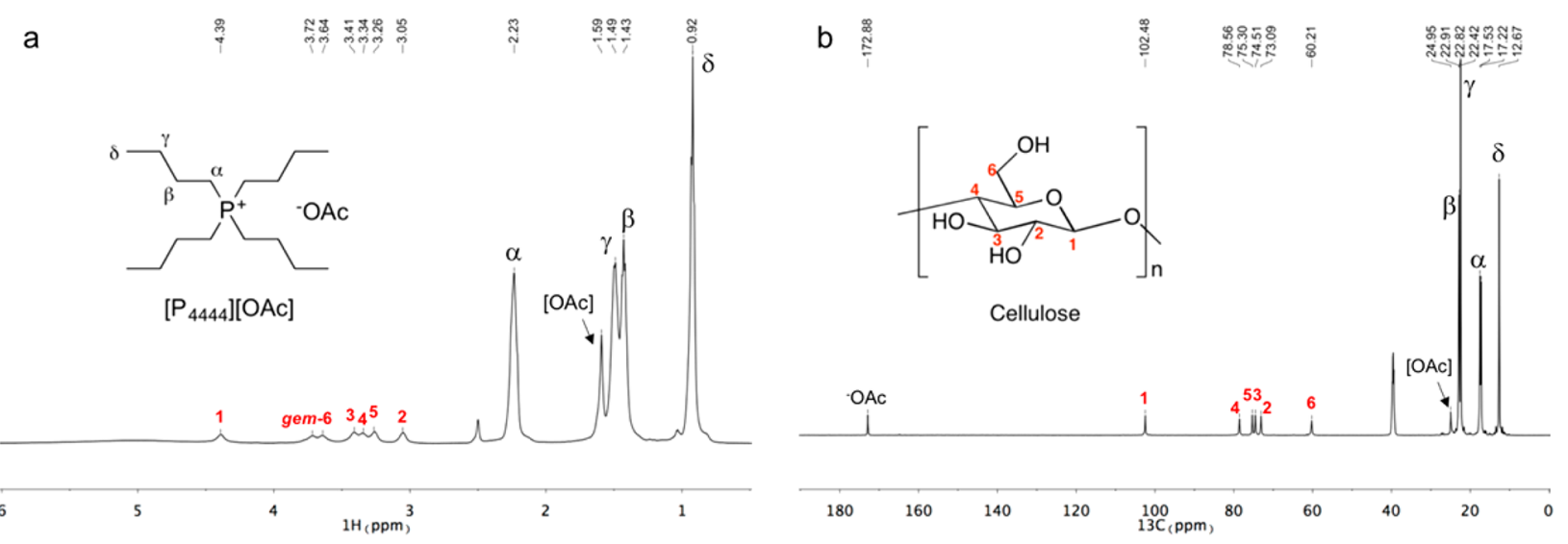

Figure 3. ${ }^{1} \mathrm{H}$ and ${ }^{13} \mathrm{C}$ spectra at $65{ }^{\circ} \mathrm{C}$ in $\left[\mathrm{P}_{4444}\right][\mathrm{OAc}]: \mathrm{DMSO}-d_{6}$ for the pristine CNCs dissolved in $\left[\mathrm{P}_{4444}\right][\mathrm{OAc}]: \mathrm{DMSO}-d_{6}(1: 4 \mathrm{w} / \mathrm{w})$.

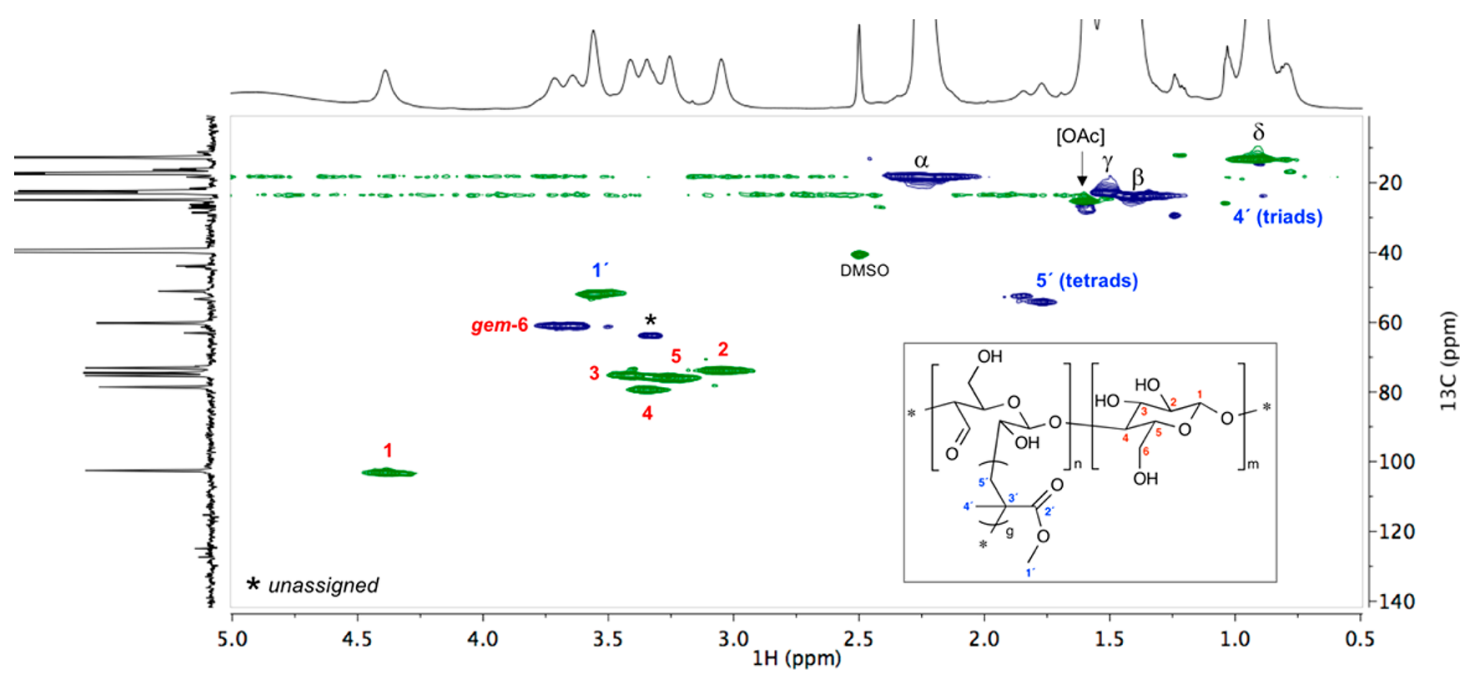

Figure 4. Multiplicity-edited HSQC spectrum at $65^{\circ} \mathrm{C}$ in $\left[\mathrm{P}_{4444}\right][\mathrm{OAc}]: \mathrm{DMSO}-d_{6}$ for PMMA-g-CNCs dissolved in $\left[\mathrm{P}_{4444}\right][\mathrm{OAc}]: \mathrm{DMSO}-d_{6}(1: 4 \mathrm{w} /$ w). The cellulose backbone resonances are numbered in red and the PMMA-graft resonances are numbered in blue.

$$
\begin{aligned}
& I_{1 \mathrm{C}}=\frac{1}{N_{\mathrm{C}}} \sum_{x=1}^{n} I_{x} \\
& R_{\mathrm{G} / \mathrm{AGU}}=\frac{I_{1 \mathrm{C}(\text { graft })}}{I_{1 \mathrm{C}(\mathrm{AGU})}} \\
& R_{\mathrm{G} / \mathrm{AGU}}=\frac{N_{\mathrm{C}(\mathrm{AGU})}}{N_{\mathrm{C}(\text { graft })}} \times \frac{\sum_{x=1}^{n} I_{\text {norm (graft) }}}{\sum_{x=1}^{n} I_{\text {norm(AGU })}} \\
& I_{\text {norm }(x)}=\frac{I_{x}}{I_{1 \mathrm{C}}} \times \frac{1}{N_{\mathrm{C}(x)}} \\
& \sigma_{\mathrm{G}}=\frac{R_{\mathrm{G} / \mathrm{AGU}}}{\mathrm{DP}_{n}}
\end{aligned}
$$

\section{RESULTS AND DISCUSSION}

Ionic Liquid Choice. While we have published the use of $\left[\mathrm{P}_{8881}\right][\mathrm{OAc}]$ for NMR analysis of high molecular weight cellulosic pulps, ${ }^{39}\left[\mathrm{P}_{4444}\right][\mathrm{OAc}]$ also dissolves cellulose sufficiently for NMR analysis, even at a dilution of $80 \mathrm{wt} \%$ DMSO- $d_{6}$. At this concentration, it was possible to dissolve up to $10 \mathrm{wt} \% \mathrm{MCC}$ in preliminary studies but practically about 8 wt \% MCC is the maximum concentration that can be easily transferred into a $5 \mathrm{~mm}$ NMR tube, due to high viscosity.
$\left[\mathrm{P}_{4444}\right][\mathrm{OAc}]$ also contains a more symmetric cation and has less atoms than $\left[\mathrm{P}_{8881}\right][\mathrm{OAc}]$, which significantly reduces the potential for overlap of resonances in the saturated alkyl chemical shift range. Previously we have also demonstrated the utility of this electrolyte in analyzing pretreated wood samples. ${ }^{55}$ When dissolving cellulose, the use of a saturated tetraalkylphosphonium cation-containing electrolyte salts allows for no overlap of solvent peaks with the cellulose backbone signals in the ${ }^{1} \mathrm{H}$ and ${ }^{13} \mathrm{C}$ spectra (Figure 3). By comparison, dialkylimidazolium-based ionic liquids, for example, 1-ethyl-3-methylimidazolium acetate ([emim][OAc]), have two $\alpha$-alkyl signals at $\sim 4 \mathrm{ppm}$; one for the 1-position and one for the 3-position on the imidazolium ring. In the ${ }^{13} \mathrm{C}$ dimension, there is no overlap between the ionic liquid resonances and cellulose backbone. However, the more critical issue for developing an NMR solvent for this purpose is to avoid reaction between the solvent and the solute. In the case of cellulose, it is well-known that [emim] [OAc] will react with cellulose, ${ }^{56,57}$ due to a combination of anion basicity and acidity at the $\mathrm{C} 2$ position in the imidazolium ring (carbene adduct formation). ${ }^{58}$ Fortunately, tetraalkylphosphoniums, with saturated alkyl chains, are much more thermally and chemically stable. They are also very effective at dissolving cellulose, but only as the electrolyte solutions with dipolar aprotic solvents, for example, DMSO. ${ }^{40}$ This does not matter as it is 


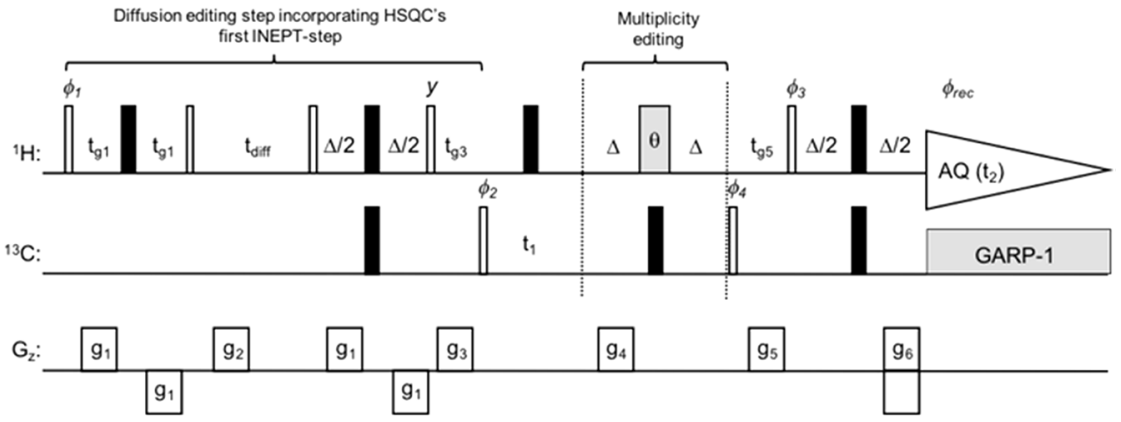

\section{Diffusion-edited HSQC}

Figure 5. Implementation of pulsed-field gradients into the gradient HSQC sequence.
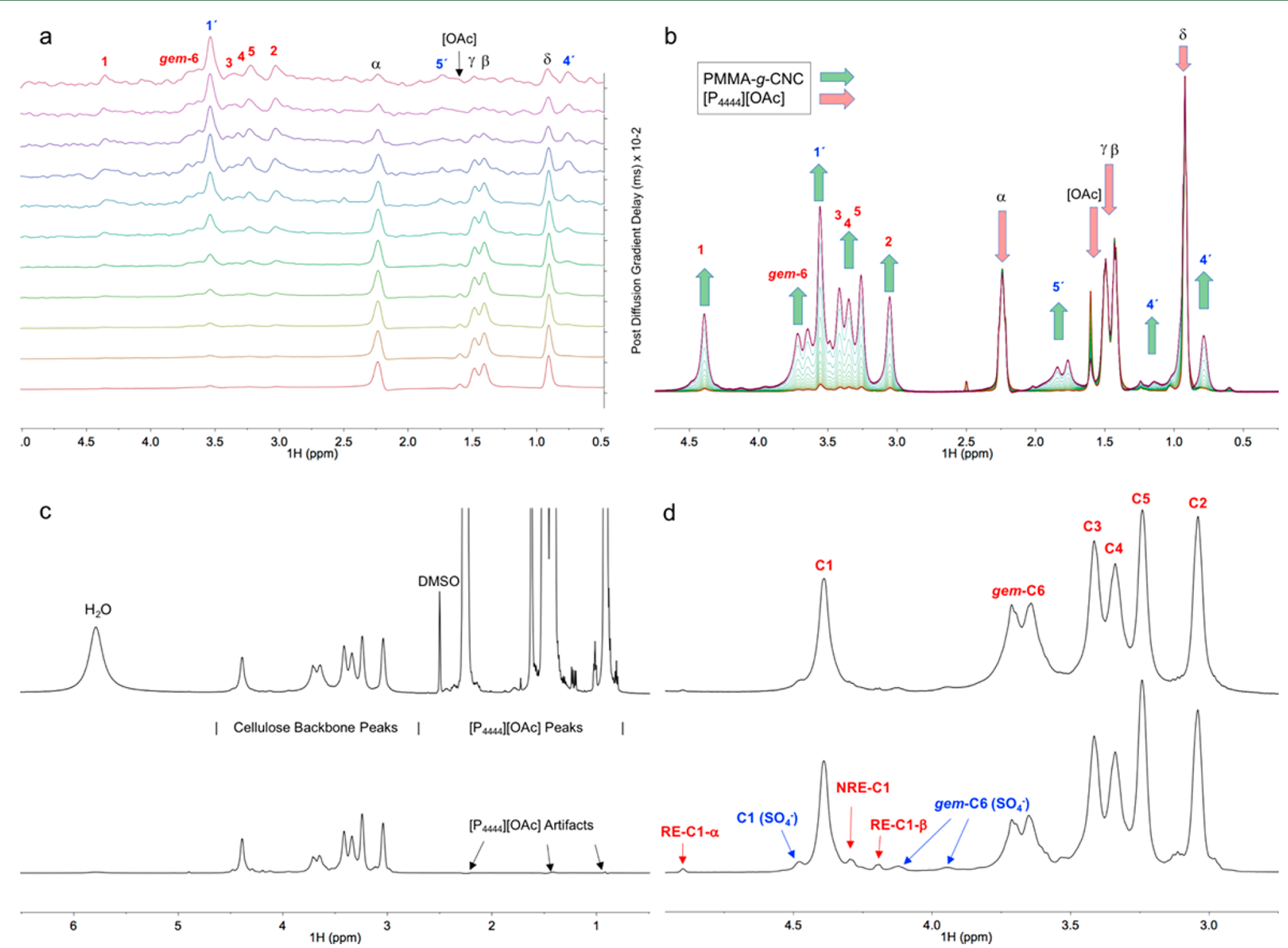

Figure 6. Spectra at $65{ }^{\circ} \mathrm{C}$ in $\left[\mathrm{P}_{4444}\right][\mathrm{OAc}]: \mathrm{DMSO}-d_{6}$ for PMMA-g-CNCs: (a) 1D HSQC array of increasing diffusion delay, using only one increment in the indirect dimension; (b) DOSY array of increasing gradient strength and ${ }^{1} \mathrm{H}$ vs diffusion-edited ${ }^{1} \mathrm{H}$ for pristine $\mathrm{CNCs}$ : (c) full spectral region and (d) cellulose backbone expansion, with ${ }^{1} \mathrm{H}$ spectra on top and diffusion-edited ${ }^{1} \mathrm{H}$ spectra at the bottom.

advantageous to use a locking solvent $\left(\mathrm{DMSO}-d_{6}\right)$ in any case. In addition, the more molecular cosolvent there is, the lower the viscosity and therefore the higher the resolution, as long as the dissolving power of the mixture does not suffer.

Initial 2D Resonance Assignments and Resolution. A multiplicity-edited HSQC was performed on the PMMA-gCNCs dissolved in $\left[\mathrm{P}_{4444}\right][\mathrm{OAc}]: \mathrm{DMSO}-d_{6}$ (Figure 4). An experiment temperature of $65{ }^{\circ} \mathrm{C}$ was found to be the most suitable temperature to maximize resolution and $\mathrm{S} / \mathrm{N}$. It was thought that higher temperatures might start to significantly degrade the cellulosic components, especially for the longer collection times. In addition, increasing above $65^{\circ} \mathrm{C}$, for pure cellulose at least, does not seem to improve the signal resolution significantly.

From Figure 4, the cellulose backbone peaks (Figure 4, in red numbering) are all clearly resolved from the grafted PMMA chains (Figure 4, blue numbering). It is also visible at this stage that the meso-racemo tetrads for $5^{\prime}-\mathrm{CH}_{2} \mathrm{~s}$ in the PMMA chains are identifiable. However, the highly abundant ionic liquid peaks are overlapping with the PMMA 4'-Me triads, generally producing weak quadrature images (artifacts) and phasing problems (particularly with the multiplicity-edited spectra). In 

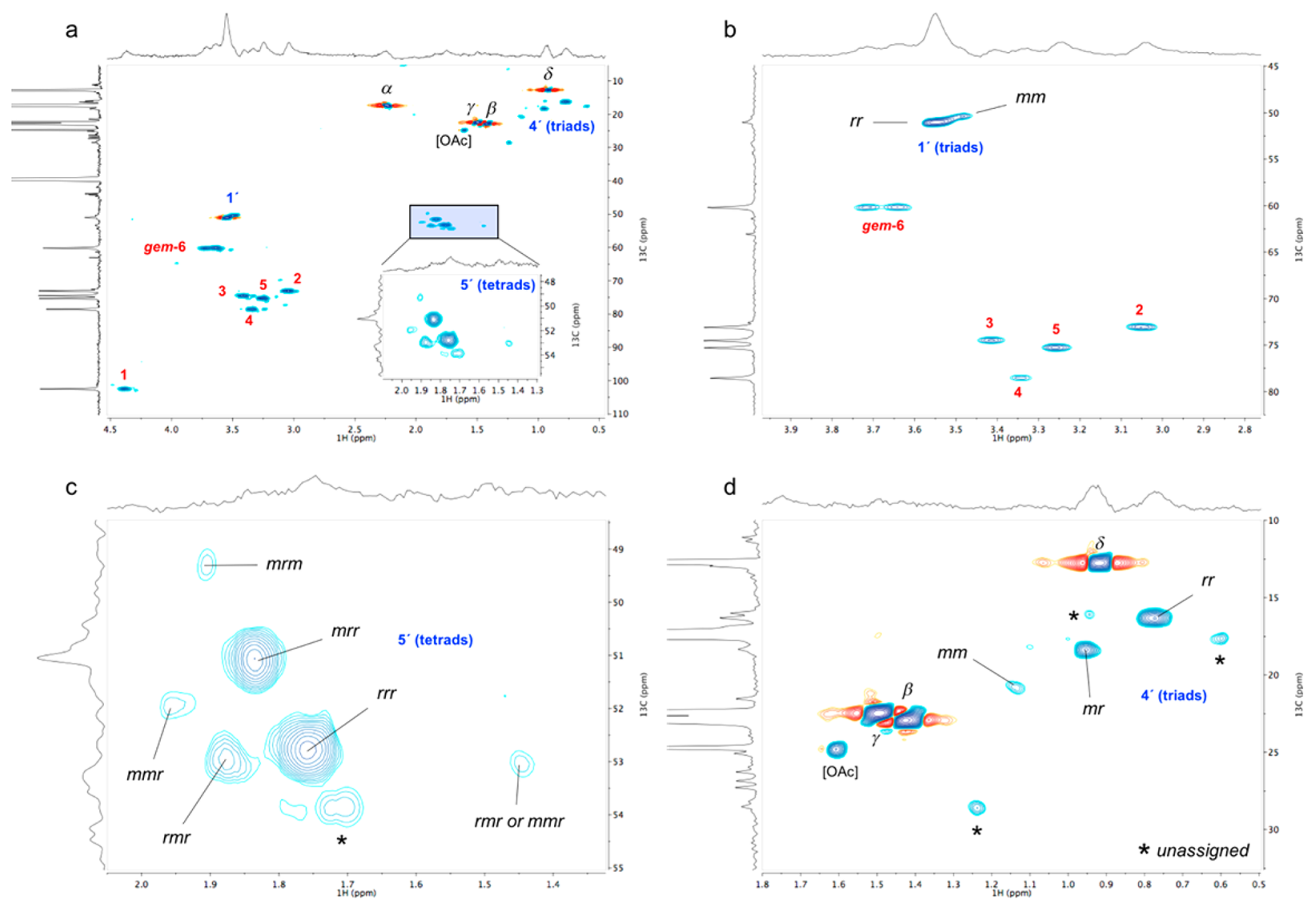

Figure 7. Diffusion-edited HSQC spectra at $65^{\circ} \mathrm{C}$ in $\left[\mathrm{P}_{4444}\right][\mathrm{OAc}]: \mathrm{DMSO}-d_{6}$ for PMMA-g-CNC in $\left[\mathrm{P}_{4444}\right][\mathrm{OAc}]: \mathrm{DMSO}-d_{6}:(\mathrm{a})$ full spectrum, $(\mathrm{b})$ PMMA-graft $1^{\prime}$-OMe triad region, (c) PMMA-graft $5^{\prime}-\mathrm{CH}_{2}$ tetrad region, (d) PMMA-graft $4^{\prime}$-Me triad region. All spectra were apodized using Gaussian $(25 \mathrm{~Hz})$ and TRAF $(25 \mathrm{~Hz})$ window functions. The negative artifacts appearing at the $1^{\prime}, \alpha, \beta, \gamma$, and $\delta$ resonances result from the application of the TRAF function.

general, good resolution of, and $\mathrm{S} / \mathrm{N}$ for, the relevant crosspeaks (close to the ionic liquid signals), relative to the cellulose backbone (outside of the ionic liquid signal range), are not adequate. Thus, we sought methods to further improve the spectral quality.

Diffusion-Editing for Additional Spectral Quality. An obvious method to differentiate between high and lowmolecular weight species is the application of DOSY NMR. This can be implemented as a $1 \mathrm{D}{ }^{1} \mathrm{H}$ experiment or incorporated into the HSQC pulse sequence (Figure 5). The $1 \mathrm{D}$ sequence that was used is essentially a CC-BPPSTE DOSY experiment, where a single gradient is chosen which attenuates the fast-diffusing species. Convection compensation was found to be necessary, after heating to $65^{\circ} \mathrm{C}$, to give almost complete removal of the fast-diffusing species. For the HSQC experiment, the sequence is an extension of the standard gradient$\mathrm{HSQC}^{43}$ with bipolar gradient pulse pairs (BPPSTE). ${ }^{41}$

Using this sequence, we found it possible to optimize the conditions for attenuation of the $\left[\mathrm{P}_{4444}\right][\mathrm{OAc}]$ signals from the 1D diffusion-edited HSQC, by maximizing the diffusion gradient pulse (strength and duration), followed by optimizing the diffusion delay time (ms). An array of increasing delay times showed the gradual disappearance of the $\left[\mathrm{P}_{4444}\right][\mathrm{OAc}]$ signals and evolution of both the cellulose backbone and PMMA-graft signals (Figure 6a). Similarly, optimization of the DOSY (BPPSTE) experiment yielded a gradient array, stacked, and normalized to the largest peak, which demonstrated the same trend, expectedly with much better relative $\mathrm{S} / \mathrm{N}$ for solute (polymeric) versus ionic liquid peaks (Figure $6 \mathrm{~b}$ ). Even from the ${ }^{1} \mathrm{H}$ DOSY we can see clear emergence of the PMMA-graft resonances, which greatly aids in identifying the polymeric material. As an additional example of the efficiency of the sequence for attenuation of the fast-diffusing species, a diffusion-edited spectrum compared to the simple ${ }^{1} \mathrm{H}$ spectrum, for the pristine CNCs, was run (Figure 6c). Figure 6c shows the full spectral region for the ${ }^{1} \mathrm{H}$ (top) versus the diffusion-edited ${ }^{1} \mathrm{H}$ (bottom). Almost complete attenuation of the fast-diffusing species is possible. Some proportion of the fast-relaxing (polymeric) species are also lost using this pulse sequence and delay time, due to relaxation prior to acquisition. This has the consequence of slightly increasing the resolution of the peaks but also enhancing the signal intensities for the reducing end (RE) and nonreducing end (NRE) groups, relative to the bulk polymeric signals (Figure 6d). This is due to the fact that the terminal units are typically more mobile than the polymeric units. This results in slower relaxation, hence, increased resolution and intensity. However, relative species abundances are lost. Thus, this should not be regarded as a quantitative method but useful for discrimination between more and less (locally and translationally) mobile species.

After the promising application of $1 \mathrm{D}$ diffusion-editing, we analyzed the PMMA-g-CNC sample using the 2D diffusionedited HSQC sequence, which yielded a spectrum where we could significantly suppress the $\left[\mathrm{P}_{4444}\right][\mathrm{OAc}]$ signals, maximizing the gain and thus dynamic range (Figure $7 \mathrm{a}$ ). However, incorporating additional elements into the already long HSQC 
pulse sequence is still expected to reduce $\mathrm{S} / \mathrm{N}$ due to longitudinal $\left(T_{1}\right)$ and transverse $\left(T_{2}\right)$ relaxation.

Especially rapid $T_{2}$ relaxation is typically observed for most of the rigid cellulose and PMMA polymer resonances and a significant amount of magnetization can be lost before acquisition begins ( $T_{1}$ and $T_{2}$ coefficients were determined and presented in the Supporting Information, Table S1 for the 5 wt \% solutions of pristine CNCs and SI-PMMA). Luckily, the second diffusion gradient period can be incorporated into the INEPT propagator $(\Delta / 2$ delays, Figure 5$)$. This minimizes losses of $\mathrm{S} / \mathrm{N}$ due to $T_{2}$ relaxation. Thus, the slower $T_{1}$ relaxation rate is the limiting factor for the maximum usable diffusion delay. The $T_{1}$ relaxation is not characteristically as rapid as the $T_{2}$. Fairly long diffusion delays (between 100 and $400 \mathrm{~ms}$ ) are possible to enhance the attenuation of the fastdiffusing species, as ${ }^{1} \mathrm{H} \mathrm{T}_{1}$ coefficients for the pristine CNCs and SI-PMMA are all approximately $2 \mathrm{~s}$ (Supporting Information, Table S1). However, relaxation during the pulse sequence is unavoidable and ultimately affects the quantitivity of $2 \mathrm{D}$ and diffusion-edited ${ }^{1} \mathrm{H}$ experiments. This is especially important for macromolecules with slow dynamics, such as polymeric mixtures at high concentration. Minimizing polymer concentration would have the effect of increasing $T_{2}$ values overall, but at the cost of a loss in $S / N$. As there is a loss in $S / N$ overall, after applying the diffusion-editing delay, the number of transients was increased to get similar $\mathrm{S} / \mathrm{N}$ to the original HSQC experiment applied to the PMMA-g-CNCs. From the diffusion-edited HSQC we can see excellent resolution for the PMMA-graft 4'-Me (triad) and PMMA-graft $\mathrm{CH}_{2}$ (tetrad) regions. However, the baseline noise is visible (Supporting Information, Figure S9). Thus, we applied a Gaussian window function (25 Hz line broadening) to the FID, in the direct ${ }^{1} \mathrm{H}$ dimension (cosine squared in the indirect dimension, although the standard Gaussian yielded similar results), in a bid to increase $\mathrm{S} / \mathrm{N}$ at the expense of resolution, followed by a Traficante (TRAF, $25 \mathrm{~Hz})^{59}$ window function to further improve resolution (Figure 7a). This allowed for a good improvement in both $\mathrm{S} / \mathrm{N}$ and resolution over the whole spectral region, at the expense of some truncation artifacts. The somewhat harsh $25 \mathrm{~Hz}$ line broadening values in the apodization were chosen to match the approximate line width/decay of the polymeric signals, thus, did not degrade the resolution much in practice. The slow relaxing fast diffusing species, that is, $\left[\mathrm{P}_{4444}\right][\mathrm{OAc}], \mathrm{DMSO}$, and other low molecular weight impurities are of course affected. While resolution can be improved somewhat, the use of both TRAF and Gaussian functions do not offer a significant increase in $\mathrm{S} / \mathrm{N}$ and resolution over less harsh Gaussian functions only.

After processing the diffusion-edited HSQC, resolution was sufficient to assign and separate the different peaks in the PMMA-graft $5^{\prime}-\mathrm{CH}_{2}$ tetrad region (Figure $7 \mathrm{c}$ ). Assignments are based on previous assignments by Brar et al. ${ }^{60}$ However, new peaks are also apparent that do not have previous assignment in the literature. Similarly, the PMMA-graft $4^{\prime}$-Me region (Figure $7 \mathrm{~d}$ ) yielded three peaks that agreed with literature assignments by Goñi et al. ${ }^{61}$ Some minor unassigned peaks of unknown origin are also visible in this region. However, application of the CPMG-edited HSQC (Supporting Information, Figure S9) has identified one of these peaks (1.24/28.59 ppm) as a low molecular weight impurity, possibly arising from the solvent. Some separation of the PMMA-graft ester 1 '-OMe, into two relatively distinct peaks, is also apparent (Figure $7 \mathrm{~b}$ ). An article by Nishiura et al. ${ }^{62}$ suggests that the major peak is the racemo- racemo triad and the smaller the meso-meso triad. Unambiguous assignments could not be made or found in the literature for these peaks but from the rough relative intensity of the peaks (Figure $7 \mathrm{~b}$ ), compared to the triad peaks in the PMMAgraft $4^{\prime}-\mathrm{Me}$ region (Figure $7 \mathrm{~d}$, racemo-racemo clearly in excess), the Nishiura assignments ${ }^{61}$ seem to be correct.

Quantification: Graft Ratio. Now that it is possible to assign the expected resonances in the PMMA-g-CNC sample, the real value of this procedure will be in the quantification of the grafting. As mentioned previously, long pulse sequences, such as HSQC, with rigid polymeric materials suffer from attenuation of resonances with short $T_{1}$ and $T_{2}$ values. This can severely limit the potential for quantification in $2 \mathrm{D}$ experiments. Fortunately, we still have excellent resolution in the ${ }^{13} \mathrm{C}$ spectrum. Thus, a quantitative ${ }^{13} \mathrm{C}$ experiment was performed to determine the graft ratio $\left(R_{\mathrm{G} / \mathrm{AGU}}\right)$, that is, molar ratio of MMA monomer to the bulk AGU. To minimize error, this was achieved by integrating the separable cellulose peak regions against the separable PMMA peak regions and averaging the values (data in the Supporting Information, Figure S10). A graft ratio $\left(R_{\mathrm{G} / \mathrm{AGU}}\right)$ for MMA to AGU of 0.44 was determined, with relative standard deviations of $14.8 \%$ (MMA) and $2.5 \%$ (AGU) between the different integral regions. From the standard deviations, standard error for both integrals can be derived, and by combining these, the relative standard error of the graft ratio was determined to be $10.0 \%$, translating to a $95 \%$ confidence interval of approximately $0.33-0.55$ (t-distribution with 5 degrees of freedom).

The $R_{\mathrm{G} / \mathrm{AGU}}$ value determined through XPS by Kedzior et al., ${ }^{37}$ was 0.23 ; by determining the ratio of the peak areas for the PMMA carbonyl $\left(\mathrm{C}^{\prime}\right)$ and $\mathrm{C} 1$ in cellulose. While XPS is a quantitative technique to determine elemental composition, it very much depends on surface penetration depth (on the $\mathrm{nm}$ scale), thus, surface layers in heterogeneous samples give different values to the bulk sample. In addition, while XPS S/N is reasonably good, ${ }^{37}$ resolution of the different carbons is poor, requiring deconvolution to determine the area compositions. While there are these sources of error to contend with, a rough estimate for $R_{\mathrm{G} / \mathrm{AGU}}$ can be given.

Attempts were also made by Kedzior et al. ${ }^{37}$ to apply solidstate ${ }^{13} \mathrm{C}$ CP-MAS NMR in the characterization of the PMMA$g$-CNCs. While the PMMA graft resonances were visible in the ${ }^{13} \mathrm{C}$ spectrum, they show much lower $\mathrm{S} / \mathrm{N}$ over their chemical shift region, in comparison to the cellulose resonances. In this case, the solid-state technique is limited to providing information about the highly ordered phases in the cellulosic portion of the sample. In compliment to solid-state ${ }^{13} \mathrm{C} \mathrm{NMR}$, the liquid-state offers the use of well-established quantitative NMR methods, on standard spectrometers and probes. In ${ }^{13} \mathrm{C}$ $\mathrm{NMR}$, resolution of peaks in the liquid state is excellent, but the main limitation is their $\mathrm{S} / \mathrm{N}$, which can of course be improved through a number of methods, for example, by optimizing the relaxation delays and increasing experiment time, allowing a larger number of transients to be collected, using more capable equipment with higher field strength and a cryoprobe, or increasing sample temperature. Relative integral values can also be obtained much faster using a standard ${ }^{13} \mathrm{C}$ experiment (due to NOE enhancement), which may yield quantitative information through the use of calibration curves.

By contrast, ${ }^{13} \mathrm{C} \mathrm{CP}-\mathrm{MAS}$ suffers from reduced resolution, severely limiting the technique on complex samples. It is also fundamentally not a quantitative technique, due to the requirement for cross-polarization (CP). However, the use of 
calibration curves could also be applied. Quantitative single pulse (QSP), also known as direct polarization, ${ }^{13} \mathrm{C}$ MAS NMR is possible on cellulose. However, resolution is still poor and the required relaxation delay times to achieve quantitative conditions are much longer (typically $>100 \mathrm{~s}$ ) than in the liquid-state, due to the very slow $T_{1}$ relaxation in the solid state at high field strengths. This yields a limited $\mathrm{S} / \mathrm{N}$, for similar collection times to liquid-state analyses. By contrast, a 5 wt \% $\mathrm{CNC}$ in the quantitative liquid-state analysis requires $13 \mathrm{~s}$ delay to achieve quantitative conditions, for a $90^{\circ}$ pulse (Supporting Information, Table S2). In addition, magic-angle spinning (MAS) of solid-state samples does not reduce the broadening of noncrystalline regions, for example, PMMA grafts. This significantly reduces the potential for accurate integration or deconvolution of the separate species.

While the liquid-state technique offers higher resolution and quantitative conditions, information about crystallinity is lost. Thus, liquid and solid-state ${ }^{13} \mathrm{C}$ NMR are complementary techniques: one offering information about crystallinity and the other offering quantitative information about chemical composition.

Quantification: Graft Length and Density. These quantitative ${ }^{13} \mathrm{C}$ results, however, do not tell us anything about the graft length $\left(\mathrm{DP}_{n}\right.$, number-average molecular weight for each graft $)$ or graft density $\left(\sigma_{\mathrm{G}}\right.$, number of graft points per bulk AGU). To determine this, we must remove the grafts from the surface of the CNCs for molecular weight determination. This was achieved by treatment of the PMMA-g-CNCs with a methanolic $\mathrm{HCl}$ solution. A methanolic solution was chosen to avoid hydrolysis of the PMMA chains. This yielded a $\mathrm{CDCl}_{3}$ soluble PMMA sample (HSQC in the Supporting Information, Figure $\mathrm{S} 1) . \mathrm{DP}_{n}$ for these grafts were determined by measuring and determining the relative (to $\mathrm{CHCl}_{3}$ ) self-diffusion coefficients $\left(D_{\mathrm{REL}}\right)$ in $\mathrm{CDCl}_{3}$. $D_{\mathrm{REL}}$ was calculated for the PMMA methyl ester peak. Monoexponential fitting was used to give a single value. $\mathrm{DP}_{n}$ was then calculated from the numerical relationship determined after measuring $D_{\mathrm{REL}}$ for PMMA gelpermeation chromatography (GPC) standards, of known $\mathrm{DP}_{n}$ values (Figure 8 and eq 2).

The $\mathrm{DP}_{n}$ value was determined to be 168 through the DOSY method. For comparison, GPC (THF eluent, Supporting Information, Figures S18-S21) was also used and $\mathrm{DP}_{n}$ was determined to be 184 , rather close to the DOSY determination.

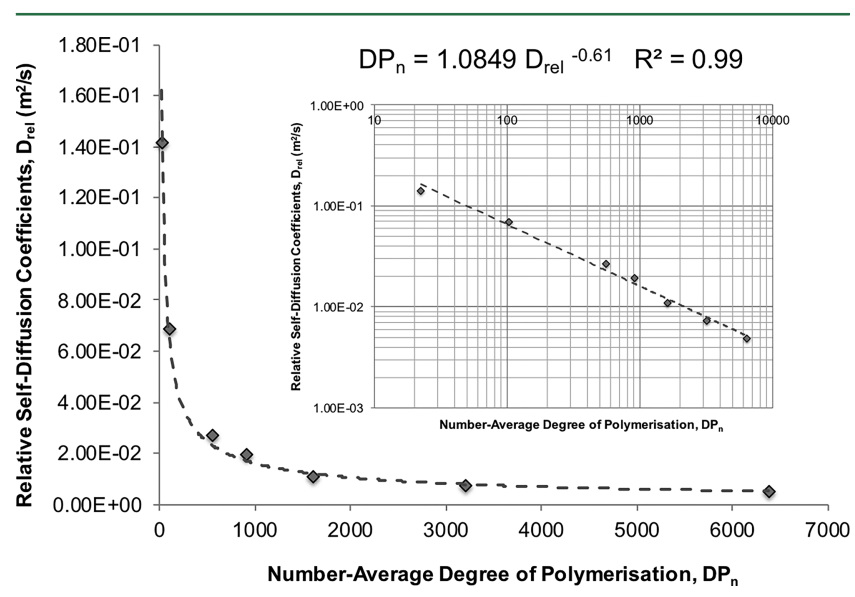

Figure 8. Master curves and equation for conversion of PMMA graft relative self-diffusion coefficient $\left(D_{\mathrm{REL}}\right)$, determined by DOSY, into the number-average degree of polymerization $\left(\mathrm{DP}_{n}\right)$.
$\mathrm{A} \mathrm{DP}_{n}$ of 168 allowed for graft density $\left(\sigma_{\mathrm{G}}\right)$ determination of 0.00261 graft points per AGU. Or, $1 / \sigma_{\mathrm{G}}$ as $382 \mathrm{AGUs}$ per PMMA graft. Or put more clearly, for a hypothetical elementary cotton CNC (cellulose source for the PMMA-gCNCs) of $\sim 25000-45000$ AGUs, ${ }^{36,63,64}$ there are only $65-117$ linkages per CNC. This is really a rather surprising result. A much higher value was expected, considering that there was $10.6 \mathrm{~mol} \%$ of CAN to bulk AGU introduced during the PMMA-g-CNC synthesis. ${ }^{37}$ It is also possible to convert $1 / \sigma_{\mathrm{G}}$ to a value that represents the surface AGUs and not the bulk. This is achieved by dividing $1 / \sigma_{\mathrm{G}}$ by 2.669 (detailed in the Supporting Information of an article by Kan et al. ${ }^{36}$ ), yielding a value of 143 surface AGUs per PMMA graft. This means there is actually $28.3 \mathrm{~mol} \%$ CAN per surface AGU, yet, with only 0.7\% (100/143) of surface AGUs functionalized with PMMA graft points. Thus, the reagent seems highly inefficient at introducing sites for radical polymerization, with most of the MMA polymerizing on a few propagating chains in the sample and as homopolymer. This is consistent with the report of Kedzior et al., ${ }^{37}$ where a lot of homopolymer was produced, requiring extensive purification to yield the pure PMMA-gCNCs.

It should be noted that there is, of course, a small error with the quantitative ${ }^{13} \mathrm{C}$, but it is not significant enough to radically alter the graft density values. Another potential source of error would be if the conditions during graft cleavage led to a reduction in the graft length. However, if degradation of the PMMA chains was occurring, this would actually yield a lower $1 / \sigma_{\mathrm{G}}$ (grafts per $\mathrm{CNC}$ ). To test that the cleavage procedure was working optimally, we also subjected the ATRP grafted filter paper, PMMA-g-FP (experimental in the Supporting Information), to the same methanolysis procedure. A sacrificial initiator was also used during the polymerization to give a secondary method of assessing molecular weight of the grafts. This is achieved by recovery of the SI-PMMA homopolymer, with the assumption that the free homopolymer follows similar polymerization kinetics to the propagating grafts on the filter paper. $^{65}$ GPC analysis of both the material recovered by sacrificial initiator and the methanolysis procedure gave $\mathrm{DP}_{n}$ values of 134 and 138 , respectively, demonstrating that no degradation of the PMMA chains was occurring.

Determining Tacticity. As we are able to discriminate between the racemo and meso diad and triad regions in the HSQC, integration of the peak volumes should allow for some rough measure of tacticity. However, there are many challenges to ensure quantitivity, especially for integration of different species. The two main issues leading to different signal intensities for species with the same number of protons attached are (1) differences in ${ }^{1} \mathrm{H}-{ }^{13} \mathrm{C}$ coupling constants and (2) differences in $T_{1}$ and $T_{2}$ relaxation. The assumption can be made that when integrating separately the triad or tetrad crosspeaks the species contributing to either the triads or tetrads are so similar that they should give relative values for cross-peak volume. This is due to the fact that their similarity, being diastereotopic in nature, should offer only small differences in the ${ }^{1} \mathrm{H}-{ }^{13} \mathrm{C}$ one-bond heteronuclear coupling constants. Similarly, there should be little difference in mobility and surrounding chemical structure of the species which will result in similar relaxation profiles. These are modest assumptions but it should be noted that trying to integrate different functionalities in polymeric materials, using standard HSQC sequences is clearly unsuitable for yielding quantitative values. In any case, it can be observed most plainly from Figure $7 \mathrm{~d}$ that 

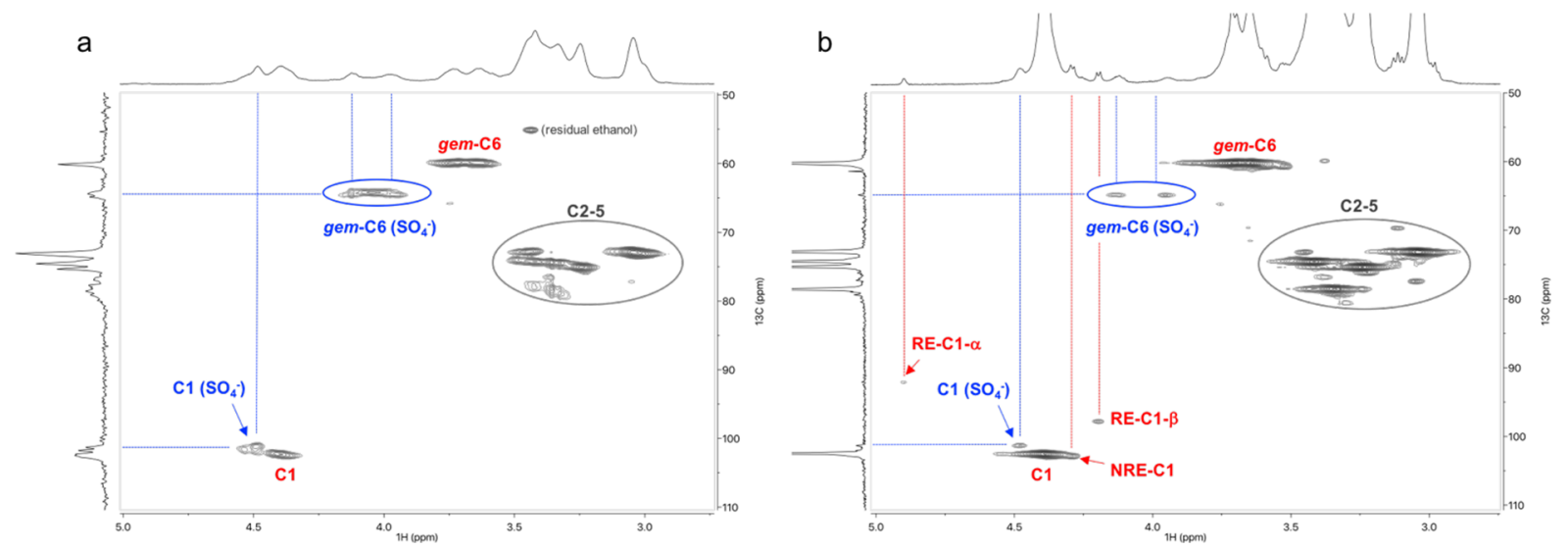

Figure 9. HSQC spectra at $65^{\circ} \mathrm{C}$ in $\left[\mathrm{P}_{4444}\right][\mathrm{OAc}]: \mathrm{DMSO}-d_{6}$ : (a) NaCS standard and (b) pristine CNCs with residual sulfate resonances; $\mathrm{RE}=$ reducing end, $\mathrm{NRE}=$ nonreducing end. ${ }^{1} \mathrm{H}$ traces are the diffusion-edited ${ }^{1} \mathrm{H}$ spectra.

there are significant proportions of both meso and racemo diads, yielding atactic PMMA grafts. This is to be expected for radicalinitiated polymerization of MMA. This may have impact on the properties of the material as atactic polymer chains prefer not to form crystalline packing phases and generally yield lower glass-transition temperatures, as demonstrated for PMMA. ${ }^{66}$

Identification of Sulfate Half Ester Resonances. As the starting CNCs were produced by sulfuric acid digestion of filter paper, ${ }^{37}$ a small proportion of the hydroxyls are functionalized as sulfate half ester groups ( $0.7 \mathrm{wt} \%$ according to " $S$ " elemental analysis, $\left.\mathrm{DS}_{\text {bulk }}=0.036, \mathrm{DS}_{\text {surface }}=0.096\right)$. This would barely be detectable using current NMR methods. There is also some question as to whether the sulfate half ester groups would be stable in the electrolyte at $65{ }^{\circ} \mathrm{C}$. According to conventional understanding of organic reactivity, they may be prone to hydrolysis from trace water in the mixture, especially in the enhanced basicity environment, or they may be prone to nucleophilic attack from the acetate anion, at the ester carbon attachment point. To solve this issue, we prepared $\mathrm{NaCS}$ through a published heterogeneous route, ${ }^{67}$ yielding a homogeneous product (experimental is given in the Supporting Information). An HSQC, in $\left[\mathrm{P}_{4444}\right][\mathrm{OAc}]: \mathrm{DMSO}-d_{6}$ at $65^{\circ} \mathrm{C}$, was measured for this sample (Figure 9a). We also measured the HSQC for the pristine CNC sample (Figure 9b). From the $\mathrm{NaCS}$ sample the $\mathrm{C} 6$ is clearly highly functionalized as sulfate half ester, gem-C6 $\left(\mathrm{SO}_{4}^{-}\right)$. Additional resonances are present in the $\mathrm{C} 1$ region that may correspond to $\mathrm{C} 1$, where either $\mathrm{C} 6, \mathrm{C} 2$, or $\mathrm{C} 3$ are functionalized as sulfate esters, $\mathrm{C} 1\left(\mathrm{SO}_{4}{ }^{-}\right)$. From the spectra for the pristine CNCs (Figures $9 \mathrm{~b}$ and $6 \mathrm{~d}$ ), there are corresponding peaks that are clearly visible in both the $1 \mathrm{D}{ }^{1} \mathrm{H}$ and ${ }^{13} \mathrm{C}$ spectra; $\mathrm{C} 6\left(\mathrm{SO}_{4}{ }^{-}\right)-\left({ }^{1} \mathrm{H}\right.$ : 3.95 and $4.13 \mathrm{ppm},{ }^{13} \mathrm{C}$ : $64.81 \mathrm{ppm}) \mathrm{C} 1\left(\mathrm{SO}_{4}{ }^{-}\right)-\left({ }^{1} \mathrm{H}: 4.48,{ }^{13} \mathrm{C}: 101.18 \mathrm{ppm}\right)$. These correspond very well with the same cross-peaks in the $\mathrm{NaCS}$ sample (Figure 9a), clearly showing the presence of sulfate half esters in the pristine CNC sample. Cross-peaks for modified C2 and $\mathrm{C} 3$ were not assigned in either HSQC spectra due to their relatively low abundance and overlap with the $\mathrm{C} 2-\mathrm{C} 5$ regions.

While we can identify these resonances in $1 \mathrm{D}$ and $2 \mathrm{D}$ experiments, accurately integrating these peaks is prone to error due to the low relative abundance of the species. Quantitative ${ }^{13} \mathrm{C}$ would require very long collection times to get sufficient $\mathrm{S} /$ $\mathrm{N}$. However, it is possible and the faster standard ${ }^{13} \mathrm{C}$ experiment would give relative values for C6 modification, which could be correlated against standard samples. Peak deconvolution of the ${ }^{1} \mathrm{H}$ spectrum is also possible but again restricted to C6 and prone to error. Even though we may not clearly identify modified C2 and C3 sulfate half esters in the pristine CNC sample, it does not mean that they are not present. In this regard, quantification of the sulfate content, based on elemental analysis, zeta potential, or XPS is definitely more robust than an NMR-only method. However, the peak assignments can take advantage of the high resolution in the ${ }^{13} \mathrm{C}$ frequency range to give positive identification of sulfate half esters, by the clear presence of the additional $\mathrm{C} 1$ and $\mathrm{C} 6$ peaks. Likewise, the geminally coupled (gem)-C6 peaks are characteristic in these ${ }^{1} \mathrm{H}$ spectra and are not significantly overlapping with $\mathrm{C} 1$ or the reducing end signals (Figure $9 \mathrm{~b}$ ). It is also interesting to note at this point that the gem-C6 $\left(\mathrm{SO}_{4}{ }^{-}\right)$signals are also visible in the ${ }^{1} \mathrm{H}$ and $\mathrm{HSQC}$ spectrum for the PMMA$g$-CNCs (Supporting Information, Figure S14), indicating no significant removal during the grafting procedure.

At present, this NMR method can be used for identification of the presence of sulfate half esters on C6 but not C2 and C3. Quantification would have to be through correlation of, preferably, ${ }^{13} \mathrm{C}$ NMR against a series of standards of known DS.

Solubility of Alternative Biopolymers. To demonstrate the potential applicability of this method beyond cellulose analytics, several other biobased polymers were also analyzed under similar dissolving conditions, allowing for ${ }^{1} \mathrm{H}$ NMR analysis (Supporting Information, Figure S15). These were silk worm (Bombyx mori) textile silk (cut from a neck tie), sheep (Ovis aries) textile wool, Norway spruce (Picea abies) galactoglucomannan (from hot water extraction), birch (Betula pendula) glucuronoxylan (from hot water extraction), chitin and chitosan (commercial, from shrimp shells). All samples were dissolved at $80{ }^{\circ} \mathrm{C}$ overnight $(18 \mathrm{~h})$. Silk and wool initially gelled and then dissolved. Chitin and chitosan both remained partially undissolved and were not characterized further. The hemicelluloses both dissolved very rapidly to give nonviscous solutions. High quality diffusion-edited ${ }^{1} \mathrm{H}$ spectra were possible for the silk, wool and hemicellulose samples, allowing for identification of polymeric signals upfield from $2.5 \mathrm{ppm} .{ }^{1} \mathrm{H}$, ${ }^{13} \mathrm{C}$, diffusion-edited HSQC, and HSQC-TOCSY were run for the silk sample (Supporting Information, Figures S16 and S17) showing excellent resolution for the peaks in both dimensions and a narrow amide proton region, indicating that the protein was most likely in an unfolded state, in solution. In addition, assignments for alanine, glycine, serine, tyrosine, and valine could be clearly identified. The chemical shifts were typical for amino acids in random coil proteins. ${ }^{68}$ 
Future Developments and Best Practice. This work was designed to demonstrate the potential for liquids NMR on modified nanocelluloses and celluloses modified to such low DS values that they are not soluble in molecular liquids, without further derivatization. So far, liquid-state analyses have been lacking due to the insolubility and general recalcitrance of nanocelluloses toward mild acid. The use of tetraalkylphosphonium acetate ionic liquids are key to the success of this due to their high chemical stability and cellulose-dissolving capability, as the DMSO- $d_{6}$ electrolyte solutions. This technique should open the door to much more thorough characterization of chemically modified nanocelluloses but can essentially be applied to all kinds of cellulose and other biopolymers, including proteins.

From the analyses described herein on cellulose, the main sources of error are in the initial quantification by ${ }^{13} \mathrm{C}$ NMR. To guarantee quantitivity, $T_{1}$ values for ${ }^{13} \mathrm{C}$ should be determined but in reality, this takes a lot of spectrometer time, due to the already poor $\mathrm{S} / \mathrm{N}$. In practice, a very conservative prerelaxation delay time of $20 \mathrm{~s}$ ( $45^{\circ}$ pulse) was applied, to get modest $\mathrm{S} / \mathrm{N}$. To give some idea of the optimum delay times to be applied, ${ }^{13} \mathrm{C} T_{1}$ values were determined for 5 wt $\%$ of the pristine CNCs $\left(\mathrm{DP}_{n} \sim 200^{62}\right)$ and the SI-PMMA $\left(\mathrm{DP}_{n}\right.$ 134). The results show that maximum observed $T_{1}$ coefficients are $0.50 \mathrm{~s}$ for cellulose $(\mathrm{C} 1-\mathrm{C} 5$ as slowest relaxing spins) and $2.65 \mathrm{~s}$ for PMMA (quaternary $\mathrm{C}^{\prime}$ as the slowest relaxing spin) when using a spectrometer of $600 \mathrm{MHz}{ }^{1} \mathrm{H}$ frequency at $5 \mathrm{wt} \%$ substrate at $65^{\circ} \mathrm{C}$ in $\left[\mathrm{P}_{4444}\right]$ [OAc]:DMSO$d_{6}$ (1:4 wt ratio). The time required for sufficient relaxation of all resonances from both polymers is then roughly $13.3 \mathrm{~s}$ for $90^{\circ}$ pulse $\left(5 \times T_{1 \max }\right)$ or $8.0 \mathrm{~s}$ for $45^{\circ}$ pulse $\left(3 \times T_{1 \max }\right)$. Relaxation of the faster moving ionic liquid ions and DMSO in solution requires longer delay times if one were to use some resonances as an internal standard. The slowest relaxing species observed are the DMSO methyl groups $\left(T_{1}=23.11 \mathrm{~s}\right)$. However, even the $\partial$-Me on the $\left[\mathrm{P}_{4444}\right]$ cation seems to relax much more rapidly $\left(T_{1}=2.08 \mathrm{~s}\right)$ and, thus, would not be the limiting factor compared to cellulose or PMMA.

The method presented herein, for cleavage of grafts was shown not to degrade PMMA under the preliminary conditions tested. In future work, variations should be validated using different well characterized samples. Within this method, hydrolysis, decarboxylation or depolymerization of PMMA may yield a polymer which has a different hydrodynamic radius in solution, which may introduce error to the molecular weight determination. However, the GPC $\mathrm{DP}_{n}$ value did not significantly differ from the DOSY-derived value. In any case, different methods must be sought for different grafted polymers. Radical-initiated polymer grafting is also an extreme case as generation of radicals is often non-chemo or -regioselective. Carbon-carbon bonds are also typically formed, which are difficult to break, possibly requiring hydrolysis of the attached sugar from the cellulose backbone. Functionality that can be introduced or cleaved through two-electron transfer processes, for example, esterifications, etherifications, should be easier to analyze, potentially allowing for assignment and integration of the attachment points or the functionality itself.

In this regard, the structure proposed in Figure 1 likely needs refinement, after further mechanistic and NMR studies. This proposed structure is based on the many historical articles on CAN-initiated grafting onto cellulose. Many studies have of course been performed but so far, no methods for liquid-state NMR analysis of modified celluloses have been available for a more accurate understanding of the mechanism, on technical substrates. A notable article by Gaylord ${ }^{69}$ discusses the mechanism, highlighting the potential for an initial complexation of $\mathrm{CAN}$ and introduction of radicals at $\mathrm{C} 2-\mathrm{C} 3, \mathrm{C} 6$, or at the reducing end. There is also strong evidence given for correlation of graft density of previous technical cellulose samples with the amount of carbonyl in the original samples, prior to modification. Thus, it is conceivable that the low graft density in this study is a result of reaction, to a large proportion, at reducing ends. This seems to be supported by the absence of reducing end peaks in the ${ }^{1} \mathrm{H}$ and diffusion-edited ${ }^{1} \mathrm{H}$ spectra for the PMMA-g-CNCs (Supporting Information, Figure S14). However, further studies would need to be performed to give a solid conclusion, preferably with lower DP nanocelluloses. Thus, in this case we have a future challenge to further improve the analytical method but with the understanding that each substrate should be considered case by case.

\section{CONCLUSIONS}

The analysis of PMMA-g-CNCs, as a difficult low DS cellulose model substrate, was demonstrated using liquid-state NMR. This was achieved by using a chemically and thermally stable tetraalkylphosphonium acetate ionic liquid in DMSO- $d_{6}$. The resolution in the ${ }^{1} \mathrm{H}$ dimension and overlap with the ionic liquid signals is expectedly not ideal for quantifying degrees of modification. However, HSQC NMR was used, in combination with diffusion-editing, to identify the polymeric resonances in the ${ }^{1} \mathrm{H}$ and ${ }^{13} \mathrm{C}$ dimensions. The high resolution of ${ }^{13} \mathrm{C} \mathrm{NMR}$ was then taken advantage of for quantification of the degree of incorporation of the MAA monomer to the bulk AGU. This cannot be achieved using solid-state ${ }^{13} \mathrm{C}$ NMR. Removal of the PMMA grafts and molecular weight determination, using both DOSY and GPC, then afforded the graft lengths and graft density, showing the accuracy of the direct diffusion-based NMR method.

The results indicated a very low number of attachment points (graft density) on the nanocrystals, compared to the amount of CAN (radical initiator) used for the modification. Thus, regioselectivity of attachment was impossible to detect, other than the tentative indications that oxidation may occur to a relatively large proportion at the reducing ends, due to the absence of clear anomeric reducing end peaks in the ${ }^{1} \mathrm{H}$ spectra. This needs further clarification in future work, preferably with lower DP nanocrystals containing unoxidized reducing ends.

The diffusion-edited HSQC improved spectral resolution, allowing for determination of the tacticity of the grafted PMMA. In general, the method is invaluable for attaining quantitative information for low DS celluloses and nanocelluloses (surface modified) in particular. This is necessary for accurate process development involving these materials. The method also greatly compliments the repertoire of available solid-state techniques, as there are no existing liquid-state analytics for such materials, due to their recalcitrant highly crystalline nature. It is fortuitous that the method is also applicable to other wood-based biopolymers and proteins.

\section{ASSOCIATED CONTENT}

\section{S Supporting Information}

The Supporting Information is available free of charge on the ACS Publications website at DOI: 10.1021/acs.biomac.8b00295. 
NMR experimental conditions and spectra of the starting filter paper, pristine CNCs, PMMA-g-CNCs, cleaved PMMA grafts and PMMA standards. Full procedures for some additional experimental, e.g., synthesis of $\mathrm{NaCS}$, PMMA-g-CNC synthesis, graft cleavage and $\left[\mathrm{P}_{4444}\right][\mathrm{OAc}]$ synthesis, are also included. $\mathrm{T}_{1}\left({ }^{1} \mathrm{H}\right.$ and ${ }^{13} \mathrm{C}$ ) and $\mathrm{T}_{2}\left({ }^{1} \mathrm{H}\right)$ values for $5 \mathrm{wt} \% \mathrm{CNC}$ or SI-PMMA are included as tabulated data. The raw GPC data for various samples is included. Larger images for the PMMA GPC standard relative self-diffusion coefficient versus $\mathrm{DP}_{n}$ correlation, diffusion-edited HSQCs and CPMG-edited HSQCs are also included. ${ }^{1} \mathrm{H}$ experiments are included for additional biopolymers, including an HSQC and HSQC-TOCSY to determine assignments for the amino acid residues in silk (PDF).

gHSQC_MWedited.c is the Varian (Agilent) sequence, combining both optional diffusion-editing and optional CPMG (T2)-editing into the multiplicity-edited (optional) HSQC sequence.hsqcedgpph_diffil.htk is the Bruker sequence for the diffusion-edited HSQC.hsqcedgpph t2fil.htk is the Bruker sequence for the CPMG (T2)-edited HSQC (ZIP)

\section{AUTHOR INFORMATION}

\section{Corresponding Authors}

*E-mail: alistair.king@helsinki.fi.

*E-mail: ilkka.kilpelainen@helsinki.fi.

ORCID

Alistair W. T. King: 0000-0003-3142-9259

Valtteri Mäkelä: 0000-0001-7264-2318

Stephanie A. Kedzior: 0000-0003-3112-3890

Harri Koskela: 0000-0002-7552-3813

Ashley J. Holding: 0000-0002-7746-7261

Emily D. Cranston: 0000-0003-4210-9787

\section{Present Address}

${ }^{\#}$ University of Calgary, Department of Chemical and Petroleum Engineering, 2500 University Drive NW, Calgary, AB T2N 1N4, Canada.

\section{Author Contributions}

The manuscript was written through contributions of all authors. All authors have given approval to the final version of the manuscript.

\section{Funding}

Academy of Finland project "WTF-Click-Nano" (311255), CLIC Innovation, HiLIFE-INFRA and Biocenter Finland.

\section{Notes}

The authors declare no competing financial interest.

\section{ACKNOWLEDGMENTS}

We would like to acknowledge our funding partner, CLIC Innovation for support on the general topic of biomass processing with ionic liquids. We would also like to acknowledge the Academy of Finland for funding under the Project "WTF-Click-Nano" (311255). The Finnish Biological NMR Center also acknowledges support from Biocenter Finland and the Helsinki Institute of Life Science infrastructure funding (HiLIFE-INFRA).

\section{ABBREVIATIONS}

[emim][OAc], 1-ethyl-3-methylimidazolium acetate; $\left[\mathrm{P}_{4444}\right]$ $[\mathrm{OAc}]$, tetra- $n$-butylphosphonium acetate; $\left[\mathrm{P}_{4444}\right] \mathrm{Cl}$, tetra- $n$ - butylphosphonium chloride; $\left[\mathrm{P}_{8881}\right][\mathrm{OAc}]$, tri-n-octylmethylphosphonium acetate; AGU, anhydroglucose unit; ATR, attenuated total-reflection; ATRP, atom-transfer radical polymerization; $\mathrm{BNC}$, bacterial nanocellulose; CAN, ceric ammonium nitrate; CC-BPPSTE, convection-compensated bipolar pulse pair stimulated echo; $\mathrm{CDCl}_{3}$, deuterated chloroform; $\mathrm{CNC}$, cellulose nanocrystal; CNF, cellulose nanofibril; $\mathrm{CP}$, cross-polarization; CPMG, Carr-Purcell-Meiboom-Gill; DMSO- $d_{6}$, perdeuterated dimethyl sulfoxide; DOSY, diffusion-ordered spectroscopy; DP, degree of polymerization; $\mathrm{DP}_{n}$, number-average degree of polymerization; $D_{\text {Polym }}$ self-diffusion coefficient for polymer in solution; $D_{\mathrm{REL}}$, relative self-diffusion coefficient; DS, degree of substitution; $D_{\text {Solv }}$, self-diffusion coefficient for the solvent; FID, free-induction decay; FTIR, Fourier-transform infrared; GPC, gel-permeation chromatography; HR, high-resolution; HSQC, heteronuclear single quantum coherence; $I_{1 C}$, cellulose $\mathrm{C} 1 \mathrm{NMR}$ integral value; INEPT, insensitive nuclei enhanced by polarization transfer; $I_{\text {norm }(x)}$, normalized integral value for region $x$; IPA, isopropyl alcohol; $I_{x}, x$-integral value; MAS, magic-angle spinning; MCC, microcrystalline cellulose; MMA, methylmethacryate; NaCS, sodium cellulose sulfate; $N_{C}$, number of carbons; $N_{\mathrm{C}(X)}$, number of carbons corresponding to integral region $X$; NOE, nuclearOverhauser effect; NRE, nonreducing end; PMMA- $g$-CNC, poly(methyl methacrylate)-grafted cellulose nanocrystal; PMMA-g-FP, poly(methyl methacrylate)-grafted filter paper; PMMA, poly(methyl methacrylate); QSP, quantitative singlepulse; $\mathrm{RE}$, reducing end; $R_{\mathrm{G} / \mathrm{AGU}}$, molar ratio of PMMA graft to cellulose; S/N, signal-to-noise; $\sigma_{G}$, graft density; SI-PMMA, homopolymer recovered after inclusion of a sacrificial initiator; TEMPO, 2,2,6,6-tetramethylpiperidin-1-yl)oxyl; TGA, thermogravimetric analysis; THF, tetrahydrofuran; TOCSY, total correlated spectroscopy; TRAF, Traficante apodization function; XPS, X-ray photoelectron spectroscopy; NMR, nuclear magnetic resonance

\section{REFERENCES}

(1) Kalia, S.; Dufresne, A.; Cherian, B. M.; Kaith, B. S.; Avérous, L.; Njuguna, J.; Nassiopoulos, E. Cellulose-based bio- and nanocomposites: A review. Int. J. Polym. Sci. 2011, 2011, 1-35.

(2) Klemm, D.; Kramer, F.; Moritz, S.; Lindström, T.; Ankerfors, M.; Gray, D.; Dorris, A. Nanocelluloses: a new family of nature-based materials. Angew. Chem., Int. Ed. 2011, 50 (24), 5438-5466.

(3) Salas, C.; Nypelö, T.; Rodriguez-Abreu, C.; Carrillo, C.; Rojas, O. $\mathrm{J}$. Nanocellulose properties and applications in colloids and interfaces. Curr. Opin. Colloid Interface Sci. 2014, 19 (5), 383-396.

(4) Lagerwall, J. P. F.; Schütz, C.; Salajkova, M.; Noh, J.; Hyun Park, J.; Scalia, G.; Bergström, L. Cellulose nanocrystal-based materials: from liquid crystal self-assembly and glass formation to multifunctional thin films. NPG Asia Mater. 2014, 6 (1), 1-12.

(5) Martin, C.; Jean, B. Nanocellulose/polymer multilayered thin films: tunable architectures towards tailored physical properties. Nord. Pulp Pap. Res. J. 2014, 29 (1), 19-30.

(6) John, M. J.; Anandjiwala, R.; Oksman, K.; Mathew, A. P. Meltspun polylactic acid fibers: Effect of cellulose nanowhiskers on processing and properties. J. Appl. Polym. Sci. 2013, 127 (1), 274-281.

(7) Hooshmand, S.; Aitomäki, Y.; Skrifvars, M.; Mathew, A. P.; Oksman, K. All-cellulose nanocomposite fibers produced by melt spinning cellulose acetate butyrate and cellulose nanocrystals. Cellulose 2014, 21 (4), 2665-2678.

(8) Blaker, J. J.; Lee, K. Y.; Walters, M.; Drouet, M.; Bismarck, A. Aligned unidirectional PLA/bacterial cellulose nanocomposite fibre reinforced PDLLA composites. React. Funct. Polym. 2014, 85, 185192. 
(9) Hooshmand, S.; Cho, S.-W.; Skrifvars, M.; Mathew, A.; Oksman, K. Melt spun cellulose nanocomposite fibres: comparison of two dispersion techniques. Plast., Rubber Compos. 2014, 43 (1), 15-24.

(10) Abitbol, T.; Marway, H.; Cranston, E. D. Surface modification of cellulose nanocrystals with cetyltrimethylammonium bromide. Nord. Pulp Pap. Res. J. 2014, 29 (1), 46-57.

(11) Hu, Z.; Ballinger, S.; Pelton, R.; Cranston, E. D. Surfactantenhanced cellulose nanocrystal Pickering emulsions. J. Colloid Interface Sci. 2015, 439, 139-148.

(12) Capron, I.; Cathala, B. Surfactant-free high internal phase emulsions stabilized by cellulose nanocrystals. Biomacromolecules 2013, 14 (2), 291-296.

(13) Kalashnikova, I.; Bizot, H.; Bertoncini, P.; Cathala, B.; Capron, I. Cellulosic nanorods of various aspect ratios for oil in water Pickering emulsions. Soft Matter 2013, 9 (3), 952.

(14) Wege, H. A.; Kim, S.; Paunov, V. N.; Zhong, Q.; Velev, O. D. Long-term stabilization of foams and emulsions with in-situ formed microparticles from hydrophobic cellulose. Langmuir 2008, 24 (17), 9245-9253.

(15) Li, M. C.; Wu, Q.; Song, K.; Qing, Y.; Wu, Y. Cellulose nanoparticles as modifiers for rheology and fluid loss in bentonite water-based fluids. ACS Appl. Mater. Interfaces 2015, 7 (8), 50065016.

(16) Ureña-Benavides, E. E.; Ao, G.; Davis, V. A.; Kitchens, C. L. Rheology and Phase Behavior of Lyotropic Cellulose Nanocrystal Suspensions. Macromolecules 2011, 44 (22), 8990-8998.

(17) Wu, Q.; Meng, Y.; Wang, S.; Li, Y.; Fu, S.; Ma, L.; Harper, D. Rheological behavior of cellulose nanocrystal suspension: Influence of concentration and aspect ratio. J. Appl. Polym. Sci. 2014, 131 (15), 18.

(18) Paunonen, S. Strength and Barrier Enhancements of Cellophane and Cellulose Derivative Films: A Review. BioResources 2013, 8 (2), 3098-3121.

(19) Khan, A.; Huq, T.; Khan, R. a.; Riedl, B.; Lacroix, M. Nanocellulose-Based Composites and Bioactive Agents for Food Packaging. Crit. Rev. Food Sci. Nutr. 2014, 54, 163-174.

(20) Li, F.; Mascheroni, E.; Piergiovanni, L. The Potential of NanoCellulose in the Packaging Field: A Review. Packag. Technol. Sci. 2015, 28, 475-508.

(21) Eichhorn, S. J. Cellulose nanowhiskers: promising materials for advanced applications. Soft Matter 2011, 7 (2), 303.

(22) Habibi, Y.; Lucia, L. A.; Rojas, O. J. Cellulose Nanocrystals: Chemistry, Self-Assembly and Applications. Chem. Rev. 2010, 110, 3479-3500.

(23) Siró, I.; Plackett, D. Microfibrillated cellulose and new nanocomposite materials: a review. Cellulose 2010, 17 (3), 459-494.

(24) Moon, R. J.; Martini, A.; Nairn, J.; Simonsen, J.; Youngblood, J. Cellulose nanomaterials review: structure, properties and nanocomposites. Chem. Soc. Rev. 2011, 40 (7), 3941-3994.

(25) Saito, T.; Nishiyama, Y.; Putaux, J. L.; Vignon, M.; Isogai, A. Homogeneous suspensions of individualized microfibrils from TEMPO-catalyzed oxidation of native cellulose. Biomacromolecules 2006, 7 (6), 1687-1691.

(26) Isogai, A.; Kato, Y. Preparation of polyuronic acid from cellulose by TEMPO-mediated oxidation. Cellulose 1998, 5 (3), 153-164.

(27) Beck-Candanedo, S.; Roman, M.; Gray, D. Effect of conditions on the properties behavior of wood cellulose nanocrystals suspensions. Biomacromolecules 2005, 6, 1048-1054.

(28) Wågberg, L.; Decher, G.; Norgren, M.; Lindström, T.; Axnäs, K. The Build-Up of Polyelectrolyte Multilayers of Microfibrillated Cellulose and Cationic Polyelectrolytes. Langmuir 2008, 24 (3), 784-795.

(29) Habibi, Y. Key advances in the chemical modification of nanocelluloses. Chem. Soc. Rev. 2014, 43 (5), 1519-1542.

(30) Carlmark, A.; Malmström, E. Atom Transfer Radical Polymerization from Cellulose Fibers at Ambient Temperature. J. Am. Chem. Soc. 2002, 124 (6), 900-901.
(31) Carlmark, A.; Malmström, E. E. ATRP grafting from cellulose fibers to create block-copolymer grafts. Biomacromolecules 2003, 4 (6), $1740-1745$.

(32) Xiao, M.; Li, S.; Chanklin, W.; Zheng, A.; Xiao, H. Surfaceinitiated atom transfer radical polymerization of butyl acrylate on cellulose microfibrils. Carbohydr. Polym. 2011, 83 (2), 512-519.

(33) Morandi, G.; Heath, L.; Thielemans, W. Cellulose nanocrystals grafted with polystyrene chains through Surface-Initiated Atom Transfer Radical Polymerization (SI-ATRP). Langmuir 2009, 25 (14), 8280-8286.

(34) Zoppe, J. O.; Habibi, Y.; Rojas, O. J.; Venditti, R. A.; Johansson, L. S.; Efimenko, K.; Österberg, M.; Laine, J. Poly(N-isopropylacrylamide) brushes grafted from cellulose nanocrystals via surface-initiated single-electron transfer living radical polymerization. Biomacromolecules 2010, 11 (10), 2683-2691.

(35) Littunen, K.; Hippi, U.; Johansson, L. S.; Österberg, M.; Tammelin, T.; Laine, J.; Seppälä, J. Free radical graft copolymerization of nanofibrillated cellulose with acrylic monomers. Carbohydr. Polym. 2011, 84 (3), 1039-1047.

(36) Kan, K. H. M.; Li, J.; Wijesekera, K.; Cranston, E. D. Polymergrafted cellulose nanocrystals as $\mathrm{pH}$-responsive reversible flocculants. Biomacromolecules 2013, 14 (9), 3130-3139.

(37) Kedzior, S. A.; Graham, L.; Moorlag, C.; Dooley, B. M.; Cranston, E. D. Poly(methyl methacrylate)-grafted cellulose nanocrystals: One-step synthesis, nanocomposite preparation, and characterization. Can. J. Chem. Eng. 2016, 94, 1-12.

(38) Klemm, D.; Philipp, B.; Heinze, T.; Heinze, U.; Wagenknecht, W. Analytical Methods in Cellulose Chemistry: Section 3.8. In Comprehensive Cellulose Chemistry; Wiley-VCH Verlag GmbH \& Co. KGaA, 1998; 2004, pp 217-222.

(39) Holding, A. J.; Mäkelä, V.; Tolonen, L.; Sixta, H.; Kilpeläinen, H.; King, A. W. T. Solution-State One- and Two-Dimensional NMR Spectroscopy of High-Molecular-Weight Cellulose. ChemSusChem 2016, 9, 880-892.

(40) Holding, A. J.; Heikkilä, M.; Kilpeläinen, I.; King, A. W. T. Amphiphilic and Phase-Separable Ionic Liquids for Biomass Processing. ChemSusChem 2014, 7, 1422-1434.

(41) Wu, D. H.; Chen, A. D.; Johnson, C. S. An Improved DiffusionOrdered Spectroscopy Experiment Incorporating Bipolar-Gradient Pulses. J. Magn. Reson., Ser. A 1995, 115, 260.

(42) Jerschow, A.; Muller, N. Suppression of Convection Artifacts in Stimulated-Echo Diffusion Experiments. Double-Stimulated-Echo Experiments. J. Magn. Reson. 1997, 125, 372.

(43) Davis, A. L.; Keeler, J.; Laue, E. D.; Moskau, D. Experiments for recording pure-absorption heteronuclear correlation spectra using pulsed field gradients. J. Magn. Reson. 1992, 98, 207-216.

(44) Kay, L. E.; Bax, A. Separation of $\mathrm{NH}$ and $\mathrm{NH}_{2}$ resonances in ${ }^{1} \mathrm{H}-$ detected heteronuclear multiple-quantum correlation spectra. J. Magn. Reson. 1989, 84, 598.

(45) Davis, D. G. Improved Multiplet Editing of Proton-Detected Heteronuclear Shift-Correlation Spectra. J. Magn. Reson. 1991, 91, 665.

(46) Schmieder, P.; Domke, T.; Norris, D. G.; Kurz, M.; Kessler, H.; Leibfritz, D. Editing of multiplicity in two- and three-dimensional heteronuclear NMR spectroscopy by fourier transformation of the pulse-angle dependency. J. Magn. Reson. 1991, 93, 430.

(47) Willker, W.; Leibfritz, D.; Kerssebaum, R.; Bermel, W. Gradient selection in inverse heteronuclear correlation spectroscopy. Magn. Reson. Chem. 1993, 31, 287.

(48) Carr, H. Y.; Purcell, E. M. Effects of Diffusion on Free Precession in Nuclear Magnetic Resonance Experiments. Phys. Rev. 1954, 94, 630-638.

(49) Meiboom, S.; Gill, D. Modified Spin-Echo Method for Measuring Nuclear Relaxation Times. Rev. Sci. Instrum. 1958, 29, 688-691.

(50) Mulder, F. A. A.; Spronk, C. A. E. M.; Slijper, M.; Kaptein, R.; Boelens, R. Improved HSQC experiments for the observation of exchange broadened signals. J. Biomol. NMR 1996, 8, 223-228.

(51) http://www.mestrelab.com. 
(52) Nilsson, M. The DOSY Toolbox: A new tool for processing

PFG NMR diffusion data. J. Magn. Reson. 2009, 200, 296-302.

(53) https://nmr.chemistry.manchester.ac.uk/.

(54) Crutchfield, C. A.; Harris, D. J. Molecular mass estimation by

PFG NMR spectroscopy. J. Magn. Reson. 2007, 185, 179-182.

(55) Deb, S.; Labafzadeh, S. R.; Liimatainen, U.; Parviainen, A.; Hauru, L. K. J.; Azhar, S.; Lawoko, M.; Kulomaa, T.; Kakko, T.; Fiskari, J.; Borrega, M.; Sixta, H.; Kilpeläinen, I.; King, A. W. T. Application of mild autohydrolysis to facilitate the dissolution of wood chips in directdissolution solvents. Green Chem. 2016, 18, 3286-3294.

(56) Liebert, T.; Heinze, T. BioResources 2008, 3, 576-601.

(57) Clough, M. T.; Geyer, K.; Hunt, P. A.; Son, S.; Vagt, U.; Welton, T. Green Chem. 2015, 17, 231-243.

(58) King, A. W. T.; Parviainen, A.; Karhunen, P.; Matikainen, J.; Hauru, L. K. J.; Sixta, H.; Kilpeläinen, I. RSC Adv. 2012, 2, 8020-8026.

(59) Traficante, D. D.; Rajabzadeh, M. Concepts Magn. Reson. 2000, $12,83-101$.

(60) Brar, A. S.; Goyal, A. K.; Hooda, S. Pure Appl. Chem. 2009, 81, $389-415$.

(61) Goñi, I.; Gurruchaga, M.; Valero, M.; Guzmán, G. M. Polymer 1992, 33, 3089-3094.

(62) Nishiura, T.; Abe, Y.; Kitayama, T. Polym. J. 2010, 42, 868-874.

(63) Elazzouzi-Hafraoui, S.; Nishiyama, Y.; Putaux, J.-L.; Heux, L.; Debreuil, F.; Rochas, C. Biomacromolecules 2008, 9, 57-65.

(64) Reid, M. S.; Villalobos, M.; Cranston, E. D. Benchmarking Cellulose Nanocrystals: From the Laboratory to Industrial Production. Langmuir 2017, 33, 1583-1598.

(65) Morandi, G.; Thielemans, W. Synthesis of Cellulose Nanocrystals Bearing Photocleavable Grafts by ATRP. Polym. Chem. 2012, 3, 1402-1407.

(66) Fox, T. G.; Garrett, B. S.; Goode, W. E.; Gratch, S.; Kincaid, J. F.; Spell, A.; Stroupe, J. D. Crystalline Polymers of Methyl Methacrylate. J. Am. Chem. Soc. 1958, 80, 1768-1769.

(67) Zeng, X.; Danquah, M. K.; Potumarthi, R.; Cao, J.; Chen, X. D.; $\mathrm{Lu}, \mathrm{Y}$. Characterization of sodium cellulose sulphate/poly-dimethyldiallyl-ammonium chloride biological capsules for immobilized cultivation of microalgae. J. Chem. Technol. Biotechnol. 2013, 88, 599-605.

(68) Wishart, D. S.; Bigam, C. G.; Holm, A.; Hodges, R. S.; Sykes, B. D. ${ }^{1} \mathrm{H},{ }^{13} \mathrm{C}$ and ${ }^{15} \mathrm{~N}$ random coil NMR chemical shifts of the common amino acids. I. Investigations of nearest-neighbor effects. J. Biomol. NMR 1995, 5, 67-81.

(69) Gaylord, N. A proposed new mechanism for catalyzed and uncatalyzed graft polymerization onto cellulose. J. Polym. Sci., Part C: Polym. Symp. 1972, 37, 153-172.

\section{NOTE ADDED AFTER ASAP PUBLICATION}

Due to a production error, this paper was published ASAP on April 11, 2018, with part of the Supporting Information missing. The corrected version was reposted on April 17, 2018. 